\title{
Guidance Note on
}

Supporting a Demographic

Transition in SSA

July 2021 


\section{About this guidance note}

This guidance note is part of the K4D Emerging Issues report series, which highlights research and emerging evidence to policymakers to help inform policies that are more resilient to the future. K4D staff researchers work with thematic experts and the UK Government's Foreign, Commonwealth \& Development Office (FCDO) to identify where new or emerging research can inform and influence policy.

This report is based on 25 days of desk-based research, carried out during January-March 2021.

K4D services are provided by a consortium of leading organisations working in international development, led by the Institute of Development Studies (IDS), with the Education Development Trust, Itad, University of Leeds Nuffield Centre for International Health and Development, Liverpool School of Tropical Medicine (LSTM), University of Birmingham International Development Department (IDD), and the University of Manchester Humanitarian and Conflict Response Institute (HCRI).

For any enquiries, please contact: helpdesk@k4d.info

\section{Author}

Evert-jan Quak

Institute of Development Studies

\section{Acknowledgements}

We would like to thank John Cleland (LSTM) and Andrew Tatem (University of Southampton), who provided advice and guidance on the development of this report and served as external expert reviewers.

We also thank the following people in FCDO, who provided suggestions for relevant literature or other advice to the author to support the preparation of this report: Joe Dashley, Susannah Pritchard, Sarah Goldsmith, Florence Vojak, David King, and Karen Eeuwens. The content of the report does not necessarily reflect the opinions of any of the experts consulted.

Editorial Coordinator: Alice Shaw

Copy-editing: Barbara Cheney

Design: Transmission

Proofreading: Karen Stubbs

\section{Suggested citation}

Quak, E. (2020). Guidance Note on

Supporting a Demographic Transition in SSA. K4D Emerging Issues Report 40.

Brighton, UK: Institute of Development Studies. DOI: 10.19088/K4D.2021.053.

\section{Copyright}

This report was prepared for the UK

Government's Foreign, Commonwealth \& Development Office (FCDO) and its partners in support of pro-poor programmes. Except where otherwise stated, it is licensed for non-commercial purposes under the terms of the Open Government Licence v3.0. $\mathrm{K} 4 \mathrm{D}$ cannot be held responsible for errors or any consequences arising from the use of information contained in this report. Any views and opinions expressed do not necessarily reflect those of $\mathrm{FCDO}, \mathrm{K} 4 \mathrm{D}$ or any other contributing organisation.

(c) Crown copyright 2021

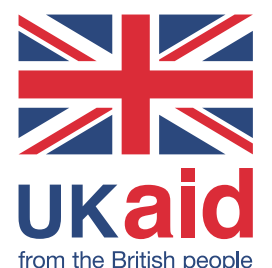




\section{Contents}

Introduction

Context and framing

Section A: Population data

07

\section{Section B: Governance}

Section C: Interventions

Direct interventions

Indirect interventions

Section D: Multisectoral approaches

Section E: Mainstreaming

Section F: Diplomacy

Section G: Engaging with Stakeholders
Using this guidance This note sets out key guiding questions and practical examples.

Symbols are used to highlight different sections, including:

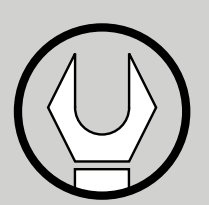

Key guiding questions

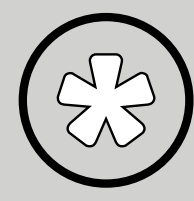

Case studies

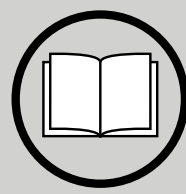

Further reading and resources

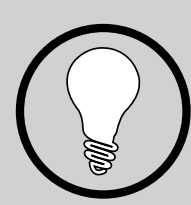

Spotlight 
This guidance note is about how donors, can support a demographic transition in subSaharan Africa. The demographic transition is the evolution from high to low mortality and fertility rates, with associated changes in age structures. Countries in sub-Saharan Africa are on a trajectory of rapid population growth. Mortality rates have been declining for some time while fertility rates started to fall later and at a slower pace, resulting in high population growth. It is estimated that the population of sub-Saharan Africa will double between 2020 and 2050 to 2.5 billion.

This guidance note refers to support from donors to governments in partner countries in two ways. First, support to adapt to the implications of rapid population growth. Second, support to accelerate the demographic transition. Countries in subSaharan Africa need to be prepared for population growth and, importantly, also for a unique "window of opportunity" that occurs when fertility rates fall consistently and at a high pace during the demographic transition. With the right investments these countries could generate economic opportunities for growth, which in the literature is called the "demographic dividend".
This guidance note is for advisers and programme managers, including senior staff and diplomats, who are developing business cases for programmes, policy, or using soft power in a wide range of sectors (including health, education, agriculture, and climate change, among others). It aims to show the breadth of factors that need to be considered in support measures for a demographic transition, while giving insights on best practices and lessons learned. As such it will help donors to:

01. Understand the importance of assessing opportunities and risks associated with demographic transition in the specific context of a country.

02. Plan new interventions and integrate demographic indicators (population dynamics) into programme design and monitoring and evaluation systems.

03. Develop a strategy for political dialogue by taking into account sensitivities and challenges.
This guidance note is not

a comprehensive guide for designing successful interventions. It does not present a comprehensive checklist or practical map that captures all required steps in decision making. Rather it provides guiding questions, practical examples, and lessons learned. The guiding questions are broad, with the purpose of shaping critical thinking and actions. However, interventions must always consider and be shaped by local contexts.

This guidance note is the product of "a Learning Journey" designed to improve capacity, understanding, and influence in seizing the opportunity to accelerate a demographic transition and potentially unlock a demographic dividend in partner countries in sub-Saharan Africa. It draws on several literature reviews that have been published during the course of the Learning Journey and learning discussions within the FCDO. It has involved a collaborative expert input and review process including FCDO advisers and academics.

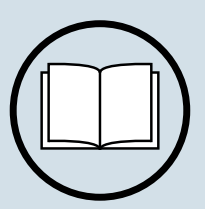

Resources:

\section{Learning Journey key resources}

The link between demography and labour markets in sub-Saharan Africa (Quak.

2021). This report investigates the evidence on how population dynamics and age structure impact on employment and labour productivity.

The linkages between population change and climate change in Africa (Price, 2020).

This report studies how interventions in the drivers of the demographic transition (e.g. family planning, education) have the potentia to be used as climate resilience measures.

The relationship between population growth age structure, conflict, and governance in sub-Saharan Africa (O'Driscoll, 2020). This report explores the linkages between demography and conflict.

Evidence of successful interventions and policies to achieve a demographic transition in sub-Saharan Africa: Ethiopia, Rwanda, and Malawi (Quak \& Tull, 2020). This report shows best practices and lessons from three champion countries in sub-Saharan Africa that achieved a fertility transition faster than other countries in the region. 


\section{Context and framing}

\section{The Demographic}

\section{Transition Model}

The Demographic Transition Model explains the stages of population growth that a country goes through, based on historical population trends of birth rate and death rate (see Figure 1). Historically, countries started at stage one in which both birth rates and death rates are high, resulting in fairly low population growth. No countries are in this stage anymore due to the introduction of modern medicine, which has lowered death rates, especially among children, even in the poorest countries.

Today, many of the least developed countries are in stage two, in which death rates gradually decline while birth rates remain high, resulting in rapid population growth. In stage three, birth rates start to decrease gradually along with a further decline in the death rates, as families choose to have fewer children. This is called the "fertility transition", which goes together with a shift from a natural fertility regime to fertility controlled by the use of contraceptives, a further reduction in mortality rate and improved education levels. In stage three, population growth continues but will gradually slow down to a lower rate. Most low- and middle-income countries are currently somewhere in this stage.

In stage four, population stabilises again with low death rates and fertility rates of around two children per woman. Some countries could even enter stage five, characterised by declining population, if the fertility rates fall below the replacement level of two children per woman and the elderly population is greater than the youthful population.

This model does not present a full picture of all population dynamics because it does not include the impact of migration. Importantly, the model cannot predict how long a country will be in each stage. Most sub-Saharan African countries are currently in stages two and three (initial stages of the fertility transition), resulting in high population growth and a youthful population.

Figure 1: Stages of the Demographic Transition Model

\begin{tabular}{c|c|c|c|c|}
$\begin{array}{c}\text { Stage 1 } \\
\text { High stationary }\end{array}$ & Stage 2 & Stage 3 & Stage 4 & Stage 5? \\
Dexpanding & Late expanding & Low Stationary & Declining?
\end{tabular}

40

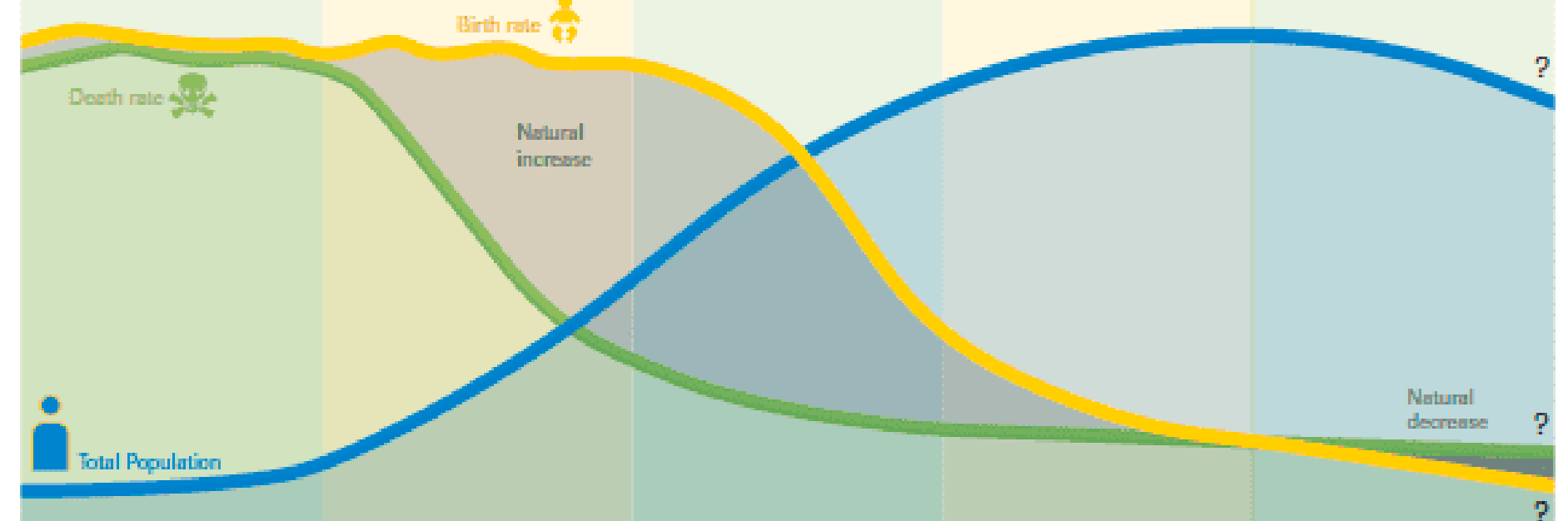

0

\section{The drivers of the}

\section{demographic transition}

- A decline in mortality rates and, in particular, a decline in infant mortality drives the fertility transition. Better health-care systems and nutrition are key to reducing mortality and increasing life expectancy. Without declines in child mortality and increased life expectancy, a desire to reduce fertility is unlikely to arise.

- The desire for smaller family sizes needs to be accompanied by the availability of methods of modern contraception. Advances in contraceptive technologies and improved access to voluntary family planning promotion have played a key role in enabling reductions in fertility.

- Another key driver is improved

education, particularly for girls and especially at secondary level. Better education delays marriage and age of first birth. When higher returns to education and human capital increase job opportunities for young women. they might decide to have fewer children. The health, education, and economic opportunities of children becomes more important than their number (i.e. quality rather than quantity).

- A combination of girls' education. women's empowerment, and access to labour markets for women is a powerful driver for the demographic transition, but only when they have access to affordable modern contraceptives. 


\section{THE DEMOGRAPHIC TRANSITION IN SUB-SAHARAN AFRICA}

\section{KEY DRIVERS}

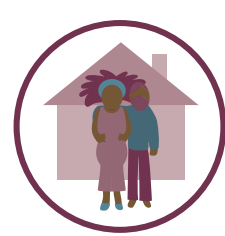

VOLUNTARY FAMILY

The unmet need for contraceptives is high in sub-saharan
Africa; on average $23 \%$ of married women aged 15-49 do not

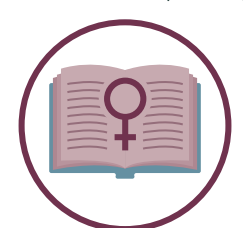

GIRLS' EDUCATION

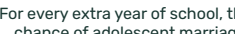

chance of adolescent marriage and $7 \%$ reduction in the

likelihood of adolescent birth. The skills acquired through
schooling increase women's earning potential and are strongly

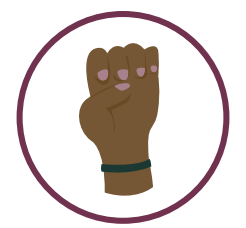

WOMEN'S ECONOMIC EMPOWERMENT

Each child reduces a woman's productive
participation in the labour market by 1.9 years.

OTHER DRIVERS:
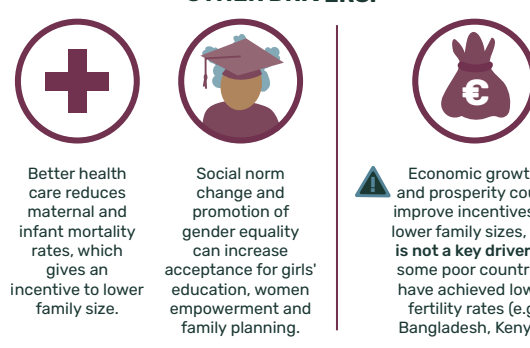

And prosperity could

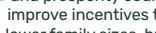

lower family sizes, bu
is not a key driver as

some poor countries
have achieved lower

fertility rates (e.g.
Bangladesh, Kenya)

\section{POPULATION DATA}

COMES FROM THREE SOURCES:

CENSUS

$(89)$

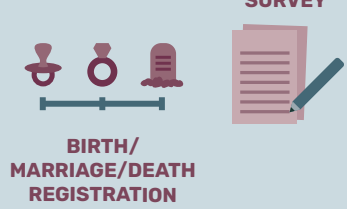

URVEY

DATA IS ONLY USEFUL WHEN: ACCESSIBLE

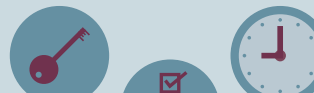

$\downarrow$
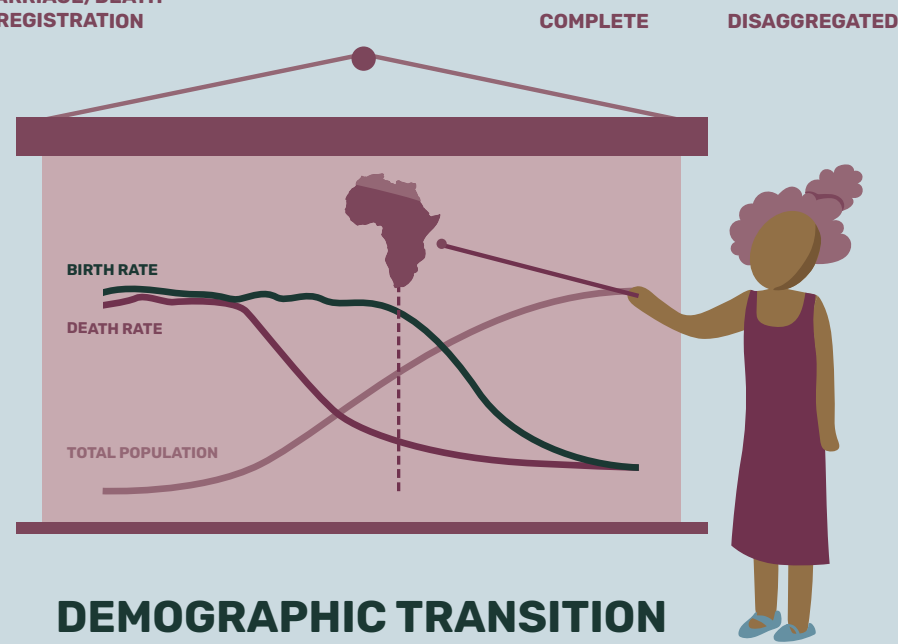

DEMOGRAPHIC TRANSITION

The demographic transition is the reduction of The population of sub-Saharan Africa is estimated time impacting on total population growth. Due to ro rate decline is rentively slow the position of sub-Saharan African countries in the was seen in other regions of the world. However, transition - with most of them still experiencing there are important differences between (and within) countries in sub-Saharan Afric. .

INTERVENTIONS \& POLICIES

1

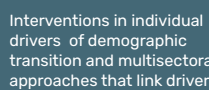

(1)
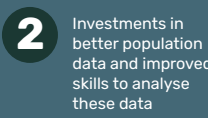

3

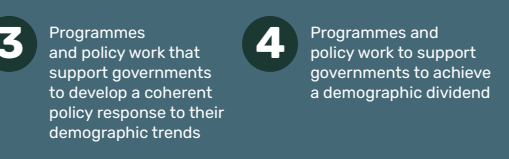

DEVELOPMENT

OUTCOMES

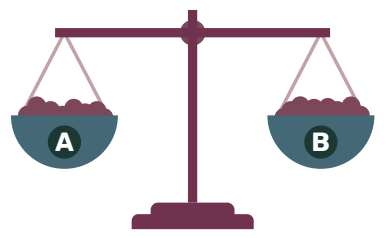

A POTENTIAL IMPLiCATIONS OF

If populations grow significantly this means every
year much more investment tis needed only to
maintin the

maintain the current tevel of GDP perc canitata as
well as capital per worker, and level of public

well as capital per worker, and
spending per pupil, patient, etc.

HIGHER CHILD HIGH PROBABILITY

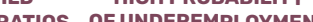

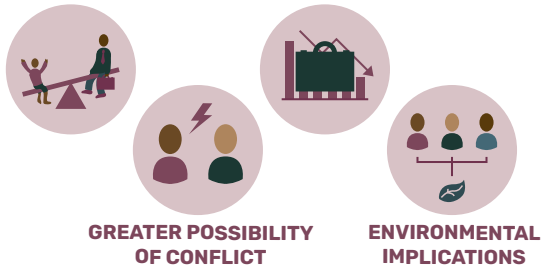

B Implications of

ACCELERATED FERTILITY DECLINE

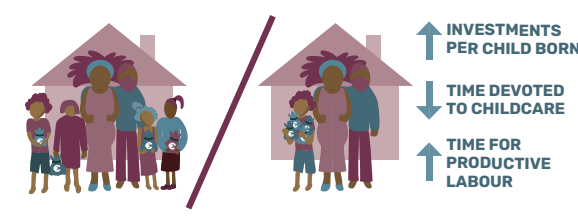

If countries are able to decrease fertility
rates faster during a period of time, this could create a 'window of opportunity' for

rapid economic growth - often
as a 'demographic dividend:

Over time this should give a new generation
better opportunities in their lifetime.

However, to capitalise on this, investments
are needed in human capital and physical

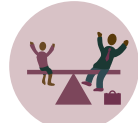

are needed in
infrastructur
. 


\section{Context and framing}

\section{The implications of the demographic transition on development}

The Demographic Transition Model (see Figure 1) shows that most sub-Saharan African countries are in the phase of rapid population growth, which results in a population with high numbers of dependent children and youth. The economic evidence shows that, when close to half the total population consists of young dependants, this has multiple negative impacts on development outcomes, such as health care, education, job creation, and labour productivity. Ultimately, this can result in higher inequalities and higher probability of conflicts. High fertility rates increase the gender equality gap, as childbearing and caring reduce women's productivity and access to better jobs. Overall, rapid population growth increases pressure on government budgets for education and health care - with the need for higher spend year in and year out, only to remain at the same expenditure level per capita. This is

\section{Multiple level policy responses to support a demographic \\ transition}

The outline of this guidance note (see right) is constructed to give insights into ways to support a demographic transition. It uses

three categories for support:

- Support to key elements of the enabling environment, such as improving population data and data analysis systems, and political and governance systems. - Development programmes, which can difficult in a context of high dependency ratios (high share of non-working-age population to total population). The growing number of new entrants to the labour market each year in sub-Saharan Africa has resulted in an "underemployment" crisis of lowproductivity jobs in the informal economy.

There is also a positive aspect. As fertility rates decline, sub-Saharan African countries will see a "window of opportunity" for economic development because the ratio of workers to dependants will rise. Most sub-Saharan African countries will face this unique opportunity in the coming decades. However, this opportunity can only be seized if they are able to increase the pace of the fertility decline (an accelerated demographic transition). To reap the benefits of a demographic dividend, governments need to invest in education, health care. and human capital. Over time, the transition to smaller family sizes becomes beneficial for families (more schooling for children better nutrition, access to labour market for women) and countries (food security. productivity, governance) be built around single interventions or multisectoral approaches that focus on the drivers of a demographic transition. It is helpful for programmes to include demographic indicators in their design and monitoring and evaluation phases, to adapt to population dynamics and making sure no one is left behind.

- Diplomacy and integrating demography and/or population dynamics within policy dialogues and engagement, which has some specific challenges and sensitivities.

\section{Guidance on understanding and improving the context}

Section A. Population data

Adequate population data collection

systems need to be in place. Quality data needs to be accessible, disaggregated, and complete.
Section B. Governance

Political leadership and commitments are needed to achieve a demographic transition. Understanding the political context is important.

\section{Guidance for programmes}

Section C. Interventions

What are the lessons

learned regarding direct

(family planning) and

indirect interventions

(girls' education, women's empowerment)?
Section D. Multisectoral approaches

Multisectoral approaches and system thinking is recommended - e.g.

integrating voluntary family planning with health, education or prosperity programmes.
Section E.

\section{Mainstreaming}

Programmes need to be aware of population dynamics and mainstream demographic information within programmes to adapt to population growth

\section{Guidance on policy dialogues}

Section F. Diplomacy

Policy dialogues on the demographic transition could be sensitive and the correct use of language is important for successful diplomacy.
Section G. Engaging with stakeholders Donors could involve local organisations in political dialogues and build bridges to engage with multiple stakeholders. 


\section{Population data}

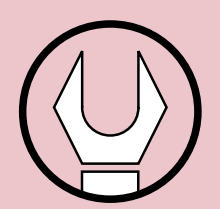

Key guiding questions: 01. What are population data?

02. Why are population data important?

03. What makes population data useful?

04 . What kinds of population data are available?

05. How important are innovative and digital technologies to improving the data landscape?

06 . How can the quality of data be assured?

07. What are the key barriers to population data collection in subSaharan Africa?

08. What kind of approaches can be used to improve population data collection and data systems?

\section{Collection and analysis for data-based development}

\section{What are population data?}

Population data describe the number of people living in a geographical area (e.g. country, province, region) where people live, and their key characteristics (e.g. age). Population data should go beyond actual counts of the living population and include breakdowns by age, sex, socioeconomic status, location, and other data that could become available through censuses, household surveys, and registry sources, such as education level, marriage status, and income. Data on fertility, mortality and migration should also be considered as population data because the interactions of these factors result in observed population dynamics. Population data should be tied to a specific time (e.g. year or month).

\section{Why are population data important?}

Population data are crucial to making the most informed decisions in development programmes. For example, they can provide information about the key characteristics of target groups, or how a programme's coverage could change over time due to population dynamics. Population data are essential to enable governments to effectively plan and allocate resources to meet their citizens' future demands for public services, human capital accumulation, infrastructure, and job creation. In the sub-Saharan African context, a

detailed understanding of the impacts of population growth on development outcomes, also related to specific geographical areas (e.g. urban vs rural), is crucial. As such, these data play a vital role in forecasting adaptations in food systems health systems, education systems, climate change responses, and labour markets.

Population data are crucial for responses in times of crisis or emergencies to identify population groups most at risk (e.g. COVID-19 responses, severe climatic events) and to target services to the right groups (e.g. social protection). Disaggregated population data are essential to identify and include a country's vulnerable people.

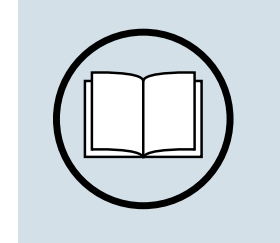

\section{Resources:}

\section{Population data entry points} The UN Population Division website is an entry point for many relevant population data sets, such as the World Population Prospects, Family Planning Indicators, and World Urbanization Prospects, amongst others.

The USAID Demographic and Health Surveys (DHS) Program provides relevant population data on its Statcompiler website.
WorldPop is an open spatial demographic data and research portal with a focus on low- and middle-income countries. It is part of the University of Southampton.

IPUMS provides a portal for census and survey data from around the world. It is part of the Institute for Social Research and Data Innovation at the University of Minnesota.

The International Household Survey Network (IHSN) is an informal network of international agencies that promotes the availability, relevance, reliability, and accessibility of survey data through a catalogue of surveys, guidelines, and access to trusted software.

The International Data Base (IDB) of the United States Census Bureau (USCB) contains population data for many countries.

The International Organization for Migration provides migration data on its Migration Data Portal. 


\section{What makes population data} useful?

- Data should be available, ideally on open data portals, to users in accessible formats. Different data systems and portals should be tailored to the needs of a variety of users, such as policymakers, practitioners, and researchers.

- Accessibility of data needs to be accompanied with improved data literacy amongst users, such as decision makers in government. Having the skills and the will to understand and use population

data is important for any evidence-based planning.

- For the data to be relevant, it needs to be updated frequently as populations change rapidly. This means that data not only needs to be accurate, but also comparable over a longer timescale.

- Population data should include all population groups. If data from marginalised groups (e.g. nomadic groups, informal settlements) is excluded, users cannot fully understand their dynamics and disadvantages.

- Population data need to be disaggregated (e.g. by geography, sex, age, disability) to understand and address inequalities.

\section{What kinds of population data} are available?

a) A census generates a wealth of data, including numbers of people, their spatial distribution, and age and sex structure, as well as their living conditions and other key socioeconomic characteristics. It allows for accurate estimates by different types of geographic area and for minority groups; it is essential for planning decisions and enables future survey results to be calculated as proportions of the population. A census provides data on the state of the population at one moment, ideally showing important issues that can be looked at in more detail in surveys.

However, because most censuses are conducted every 10 years, there is widespread use of projection methods for inter-census period estimates. This makes data less relevant and accurate over time, missing out impacts of important events such as disasters and conflicts. This method is also a very highcost exercise (USD 200 million upwards for a country of around 100 million) in which quality control is highly challenging.

b) Routine data systems of universal registration of births, deaths (and their causes), marriages, and divorces are essential for population data collection, planning. and research. These are referred to as civil registration and vital statistics (CRVS) systems and they need to be complete and accurate. As such, this real-time data can be easily disaggregated by sex and other relevant characteristics (e.g. age of marriage for women).

The registration requires sustained investment across a whole nation with incentives to the population to register vital events such as birth, death, and marriage. No low-income country has yet achieved a complete registry of vital statistics and. globally, an estimated 166 million children under the age of five are not registered. Even if coverage were to improve significantly, registering events retrospectively would present a challenge. One other major disadvantage is that such data registration systems do not capture migration and details on socioeconomic characteristics. c) Enumerators administer population surveys using standardised questionnaires to interview eligible individuals selected in a scientifically designed sample. National population surveys produce nationally representative and internationally comparable estimates of demographic, health, and social indicators for planning and monitoring and evaluation purposes. The advantage of such surveys is that they are cost-effective in filling in the gaps between censuses or the absence of effective registration systems for vital events. For example, they can explore a particular issue or research question related to a particular sub-population.

However, all sample surveys will have a sampling error determined by the sample size. As a consequence, some sample sizes of specific groups might be too small to disaggregate (e.g. people with disabilities or minority groups). It also requires an up-to-date sampling frame in order to be reliable. All surveys experience some level of non-response and, combined with the medium used (e.g. mobile phone surveys), this can lead to biased estimates. As such, understanding the methodology is very important to interpreting the data.

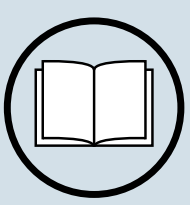

Resources:

Best practices for census, routine data systems, and surveys

\section{Census:}

- UNFPA Census quidelines and

reports and Strategy for current census round

\section{Routine data systems:}

- National CRVS context in different countries

- E-learning courses on CRVS

\section{Population surveys:}

- Demographic and Health Surveys

from over 90 countries (USAID funded)

- Multiple Indicator Cluster Surveys (MICS) (UNICEF)

- Living Standards Measurement Study (LSMS) (World Bank)

- International Household Survey Network (IHSN) 


\section{Population data}

\section{How important are innovative and digital} technologies to improving the data landscape?

Innovative and digital technologies provide opportunities to improve the data landscape in many ways; for example, with satellite imagery, use of mobile technology, biometrics, and advanced dissemination platforms and analysis tools. Geospatial technologies are increasingly used to estimate population data, while digitalisation means that there are new ways to store, analyse, and disseminate population data. Digitalisation could increase coverage, including being used in conflict situations where in-person data collection is too dangerous. It is also more cost-effective than traditional data collection exercises, such as paper-based surveys and interviews. However, new methods are unfamiliar to many national statistical offices and require advocacy and time to embed data and registration systems. Furthermore, some groups risk exclusion depending on literacy, spoken languages, disabilities, and digital skills.

\section{6 . How can the quality of data}

\section{be assured?}

Data collected through official portals (e.g. national statistical offices, UN Population Division) can generally be trusted, although it is always good to know how the data have been collected and what methodologies were used. When using census data, it is helpful to check the findings of a post enumeration survey where available. For any doubts about the quality or how to interpret population data, the best option is to inform the statistical units or experts within your organisation.

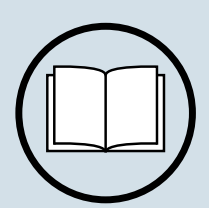

\section{Further reading:} Innovative methods to estimate population data

UNFPA's Guidance note (2020) looks at how population prediction can be modelled as a function of satellite imagery-based or geospatially derived covariate layers, such as distance to roads, night-time lights intensity or land cover classification.

\section{Wardrop et al., (2018) reviews} past and ongoing work aimed at producing spatially disaggregated local-scale population estimates and discusses how new technologies are now enabling robust and costeffective solutions.

UNFPA's Technical Brief (2019) provides information about the method and potential of combining traditional census data with the newest geospatial technology.

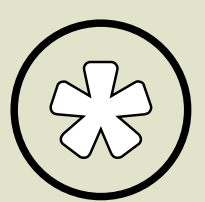

\section{Case Study:}

\section{Combining traditional and new} technologies for census

The FCDO is supporting the World Bank's Identification for Development (ID4D) programme, which is helping countries to build inclusive and trusted digital identification schemes as a route to supporting access to service and the exercising of rights. The Geo-Referenced Infrastructure and Demographic Data for Development (GRID3) programme's census method combines traditional and new technologies to produce high-resolution population estimates to address undercoverage in a traditional national census. The method relies on complete counts of population within small, defined areas, through "micro-census surveys". Statistical models are then used to link these microcensus data to spatial data extracted from satellite imagery. Satellite images have full coverage over the regions of interest and can be used to predict population numbers in the unsampled locations. By aggregating these high-resolution predictions, population totals can be produced for administrative units or for the national and subnational level to produce the most complete censuses to date in countries where full coverage through traditional censuses is not possible. 


\section{Population data}

\section{What are the key barriers to population data collection in sub-Saharan Africa?}

- Conflict, inaccessibility of some regions, and mobile populations.

- Lack of a statistical culture and limited use of data for decision making and planning in some instances.

- Acute funding problems for staff and resources to support data collection and analysis; in particular, for censuses. This has resulted in low physical and material capacity of statistical offices.

- Skills for data processing, and the statistical analysis and reporting skills required to produce statistical indicators and reports are often underdeveloped.

- Lack of upgrading of CRVS systems. The lack of infrastructure, the distance to registration offices, and the lack of buy-in to the process amongst the population in registering civil status, deaths, and births hampers improvements.
08. What kind of approaches can be used to improve population data collection and data systems?

- It is important to increase awareness, willingness, and capacity to use demographic data at high-level policy and decision-making levels for evidencebased policymaking and planning. One way to do this is to present best practices and highlight case studies that show the benefits of using demographic information at national and provincial levels. Awareness and capacities can be improved through training and skills building, tailored for each user group. This could go hand in hand with lobbying for increased domestic budgets for production, analysis, and dissemination of population data.

- Actions are needed to improve national statistical systems; for example, by

supporting the development of a national roadmap to include the necessary organisational structures, mapping possibilities for strengthening CRVS systems and also developing strategies to increase incentives for citizens for registration of vital events; and promoting the use of new technologies for geospatial mapping. It is also important to map key stakeholders in data producing and analysing by looking at their specific capacity needs, including education and research institutes.

Training and skills building improve capacities and should include the use of new technologies.
- Another action is to improve checks and balances for quality data and their accessibility. This could be done by establishing a monitoring and feedback function of data and information usage at the national and subnational levels, including data collection supervision, data checking, data editing, data imputation, data verification, data anonymisation, and data security measures.

- Action is also needed to make population data accessible and attractive to use, and open access. This includes the use of infographics, dashboards, easily downloadable data sets, etc. They could be considered for inclusion in programmes' advocacy efforts and in capacity building of local media to use data and hold governments to account. 


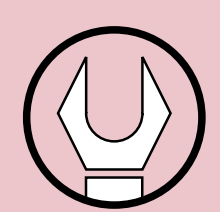

Key guiding questions:

01. Can a fertility transition be achieved without political commitment?

02. What factors affect political commitment to accelerate a fertility transition?

03. Which political stakeholders should be involved in order to successfully implement policies and strategies to accelerate a fertility transition?

04. How can policies and laws help to support and accelerate a demographic transition?

05. How effective is a population council and what factors lead to a council functioning well?

06. What should be the responsibility of decentralised authorities and regions, and how can they best be supported in their roles?

Establishing population institutions, policies, and strategies

\section{Can a fertility transition be achieved without political commitment?}

Historically, the fertility transition in Europe and much of Latin America was achieved without political commitment. In Latin America, there was a more bottom-up approach driven by civil society because authorities were reluctant to facilitate family planning in the 1970s and 1980s. However, for the poorest countries in the past 50 years, and based on voluntary family planning approaches, a significant drop in fertility rates could only be achieved with political commitment and leadership (Cleland \& Potter, 2019). This is particularly true for the champion countries in subSaharan Africa - such as Botswana, Kenya, Ethiopia, Rwanda, and Malawi - where voluntary family planning was explicitly recognised as a key contributing factor to national priorities of youth, rural development, and improved education.

In the absence of national government commitment, advocacy with ministries of financial affairs and planning, work with civil society groups, and funding international NGOs to provide voluntary family planning are some important options to consider.

\section{What factors affect} political commitment to accelerate a fertility transition?

Three important factors can be identified that may influence political commitment to a fertility transition:

- African leaders' attitudes may be constructed through their relationship with ethnic groups and local social institutions. Political leadership. therefore, often depends on the support of conservative and religious groups in society, who may oppose a radical move towards voluntary family planning services promoting modern contraceptives (May, 2017). Even if the political elites are very much in favour of lower fertility rates, they may not act accordingly in order to keep political leaders on side.

- Political leaders are often reluctant because they might not feel a sense of urgent demand in the general population. In particular, this might be the case for fragile regimes, for which improvements in physical infrastructure will always be more popular than policies for voluntary family planning services and women's empowerment.

- Many African leaders have perceived large populations to be socially, economically, and politically advantageous (May, 2017). As such, some African policymakers refer to economic growth as the main pathway for declining fertility, not family planning.
There are signals that some African leaders and policymakers are changing their attitudes and showing more commitment and leadership in favour of a fertility transition, mainly due to the prospect of the "demographic dividend", which refers to economic growth spurred by an accelerated fertility decline now widely being advocated by the African Union. Furthermore, there are signs that the youthful population in Africa is becoming more aware of their unmet needs for modern contraceptives.

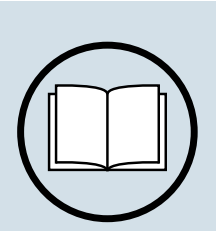

Resources:

\section{Governance, policies.} and regulation

Resources: Useful resources are: Cleland \& Potter (2019), May (2017), Quak \& Tull (2020), United Nations (2018), and USAID (2013). 
03. Which political stakeholders should be involved in order to successfully implement policies and strategies to accelerate a fertility transition?

To enact population policies, top-level support and leadership is needed from the prime minister and/or president. To get the right budget for relevant programmes (e.g. family planning, girls' education), it is important to have high-level support. commitment, and leadership at the ministry of financial affairs and planning. Key implementing ministries also need to show commitment including the ministries of health, education, and women and children's affairs. Legislative institutions, such as special parliamentary committees and influential parliamentarians, are important to keep a government thinking strategically about the future needs of its country's population and to be accountable for achieving targets.

Having a comprehensive population policy in place, which could combine strategies on migration, youth, ageing fertility, etc., is beneficial to get all relevant political stakeholders actively united around a common strategy (UN, 2018). However, it is also true that a country can instigate an effective voluntary family planning programme without any formal population policy as long as there is enough political commitment.

\section{How can policies and laws help to support and accelerate a demographic transition?}

The sub-Saharan African countries in which fertility rates have declined quicker tend to

have a clear legal and regulatory framework. defined goals and indicators, and commitment to deliver better quality family planning programmes often combined with health and education strategies. Clear laws, regulations, codes, and policies are pivotal to reduce unintended births and unmet need for contraceptives as they protect individual reproductive rights and represent political commitment to develop systems that support these rights. Dismantling of laws or guidelines that reduce access to contraception (e.g. requirement of a husband's written permission or preventing young women from use of specific methods) are of particular importance. Laws and policies can also set standards for family planning financing and for the regulation of contraceptive quality. Furthermore, policy plays a critical role in scaling up and sustaining interventions.

Specifically, child marriage laws, abortion laws, and laws on equity of education all contribute to a rights-based approach. Making it illegal to marry before 18 years of age, for example, is a factor in delaying the age of marriage, which could contribute to fertility decline.

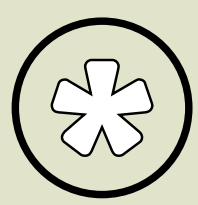

\section{Case study:}

\section{Policy reforms in Malawi}

In Malawi, the 2013 Gender Equality Act guarantees access to reproductive health care and bars discrimination in providing services based on marital status (Rosen et al., 2017). This law aims to promote gender equality; specifically, it calls for equal integration, influence, empowerment, dignity, and opportunities for men and women in all areas of society. It also prohibits and provides redress for sex discrimination, harmful practices, and sexual harassment. Finally, it provides for public awareness on the promotion of gender equality and related matters. Malawi also raised the minimum legal age of marriage to 18 in 2015 However, Parliament still needs to change the Constitution for the law to be properly upheld as the Constitution states that youth aged between 15 and 18 can be married with the consent of their parents or guardians. In Malawi, there are also talks to revise the very strict current abortion law (Daire et al., 2018). The Penal Code, which dates back to the colonial era, allows abortion only to save the life of the woman. In 2015, the Malawi Law Commission released its draft Termination of Pregnancy bill that proposes liberal changes which, if implemented, would expand access to safe abortion. However, it has not yet been put to Parliament by the government. 


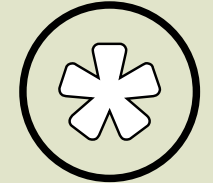

\section{Case study}

Population policy in Nigeria

In 1988, Nigeria followed Kenya and

Ghana with a population policy with the aim of slowing population growth. At the national level, there was commitment from a technocratic elite, driven by the Minister of Health. Although the policy was part of governance processes and set rules for the relationship between citizens and the state, and despite the government commitments and leadership, it was not enough for a pronatalist population to accept and adopt the population policy. The policy did not seek important partnerships

with women's groups and religious leaders. Sullivan Robinson (2012) concluded that "This finding indicates that local characteristics can matter in policy diffusion, and certainly influence what happens after policy adoption."

\section{How effective is a population council and what factors lead to a council functioning well?}

Although it is difficult to generalise, it seems that population councils can enhance cross-sectoral collaboration and can be successful as they get the freedom to engage with local experts, research institutes, civil society, the media, and development partners. However, there are also countries, such as Zambia, that have achieved the same through existing government departments. In order to have teeth, the population council (a) must sit in a ministry with real power, preferably within the ministry of financial affairs and planning; (b) should receive political support from the prime minister and/or president; and (c) must be led by someone respected across multiple departments and who combines a good understanding of politics and financing with overall knowledge of population dynamics and their implications on development. As such it is important to avoid the challenge of a population council being siloed into a sector department, such as a ministry of health. Under such circumstances, advocacy and support for a population council could be considered.

\section{What should be the}

responsibilities of decentralised authorities and regions, and how can they best be supported in

\section{their roles?}

In sub-Saharan Africa, polices, targets, laws,

and programmes on voluntary family planning. girls' education, women's participation in

labour markets - which are amongst the most effective for a fertility transition - are mostly set centrally and implemented without much regional variation. Implementation powers and incentives to strengthen

commitments at the provincial and local levels should be accompanied by good understanding of local needs and barriers. Much depends on linguistic and cultural diversity, which determines the need for varying communication efforts to different ethnic groups. As such, budgets need to be allocated sufficiently and equally by taking into account the specific needs in different regions in a country. This includes good information

systems within government from the local to the central and vice versa.

In terms of family planning and girls

education programmes, there is evidence that decentralisation has increased access for rura populations by bringing the infrastructure closer to the people. Decentralisation also could stimulate participatory decision-making structures on local implementation and in projects (e.g. with youth), improve value chain management, and give some budgetary

freedom at local levels. An option is to add population officers to district development committees and stimulate collaboration with local civil society, community-based organisations, and local private sector actors.

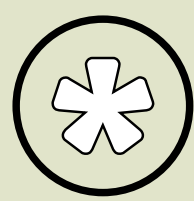

\section{Case study}

\section{Decentralisation in Rwanda}

Territorial decentralisation of

family planning programmes was crucial in Rwanda, where $70 \%$ of

the population live in rural areas. Decentralising the health-care system also allowed the programme to incorporate the needs of different communities in the decision-making process (Schwandt et al., 2018).

In collaboration with development partners, the Ministry of Health has invested in innovative interventions, including on family planning, within an increasingly decentralised healthcare delivery system (Lantos, 2019).

Source: Schwandt et al. (2018): Lantos (2019). 


\section{Interventions}

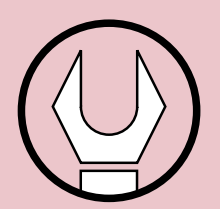

Key guiding questions:

01. What direct interventions

have proven to be effective

in advancing a demographic

transition?

02. How can quality voluntary family planning programmes best be designed?

Interventions that work well to accelerate a demographic transition Direct interventions

\section{What direct interventions} have proven to be effective in advancing a demographic transition?

The literature is clear that family planning is the only direct intervention that can have an impact on fertility rates. There is also clear evidence that interventions in girls' education have strong causality with reduced fertility, although debate continues on what exact mechanisms are behind it (e.g. higher status, higher income, delayed marriage, better knowledge of how to use modern contraceptive methods, better health knowledge) (Liu \& Raftery, 2020).

In any support to advance a

demographic transition it is therefore recommended to provide women and couples with access to and information about contraceptive methods - the main goal of family planning programmes. Family planning should always be rights-based and voluntary and preferably be integrated within a multisectoral approach that includes education and health programmes (see section D).
Supporting an increase in the uptake of voluntary family planning has proven to be more difficult in a less educated population but, as demonstrated in Ethiopia, can be achieved. The education status of women of reproductive age (i.e. secondary education) is more important for fertility than enrolment levels of children. A more educated girl is likely to have fewer children so she can invest more in their development. Studies show that a more educated population also results in lower child mortality (see "Indirect interventions", next page). 


\section{SUPPORTING VOLUNTARY FAMILY PLANNING}

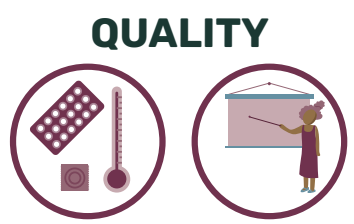

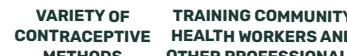

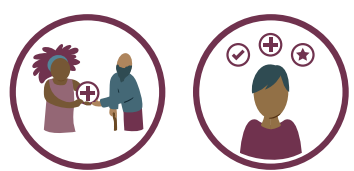

INTEGRATED
SERVICES

EFFICIENCY

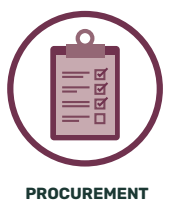

(1||||||||

LOGISTICS
AND SUPPLY
PARTNERSHIPS WITH

EQUITY
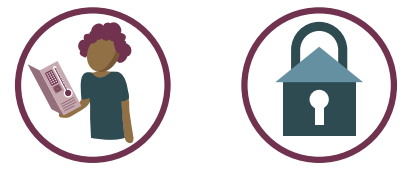

TALLORED SERVICES

ACCESS TO SECURE LOCATION
WHERE PEOPLE CAN COME
SAFELY AND FEEL CONFIDENT

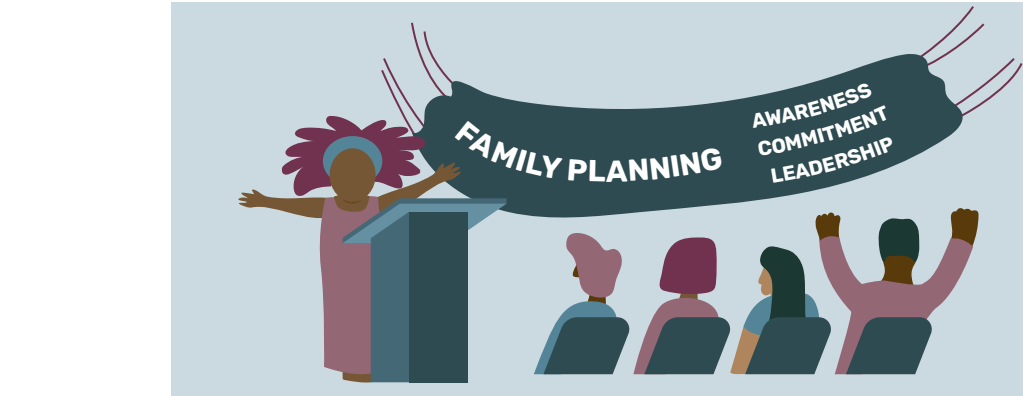

POLITICAL ENABLING ENVIRONMENT
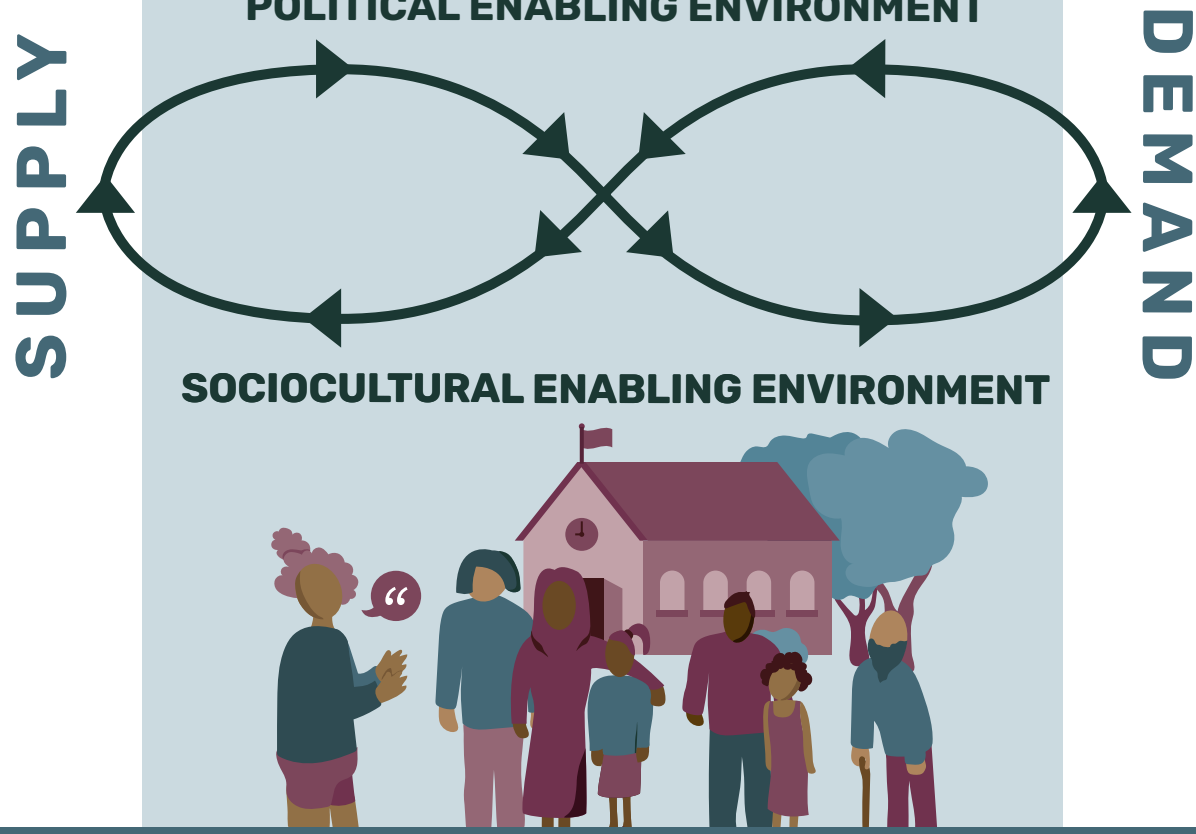

IMPLICATIONS FOR PROGRAMMING

1

DESIGN

Family planning programmes can operate independent/,
but it is better to integratete them in other programmes.

For example, education programmes (sex education.
consultations), health programmes (integrating fam

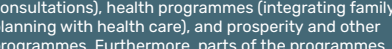

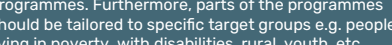

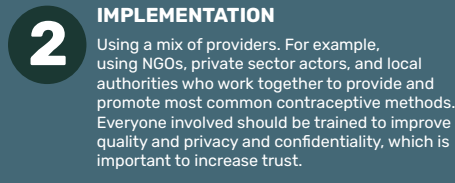

3

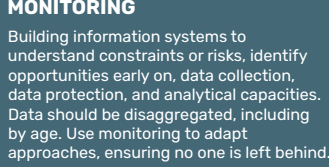
POLICY DIALOGUE
Improving governance and
accountability, engaging with
stakeholders at all levels to
improve the political and
social enabling environment.
INCENTIVES

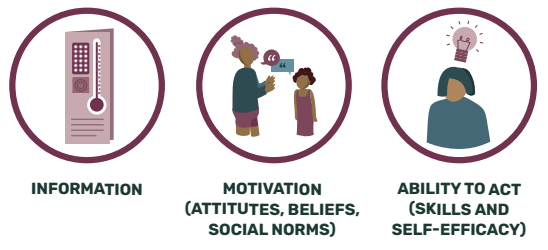

CHANNELS

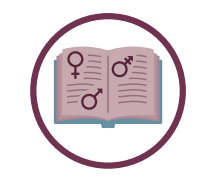

COMPREHENSIVE SEXUAL

AN
AND RILOHTS EDUCATION
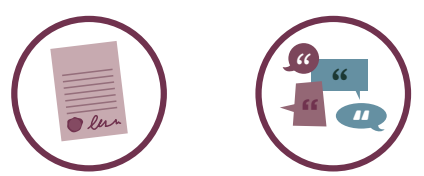
PROGRESSIVE
POLICIES AND

GDING WOMITYMOBILLISATION
MEN, TRADITION

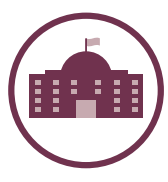

GOVERNANCE AND

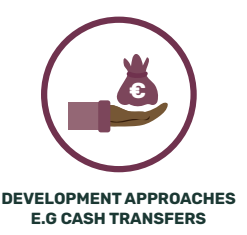

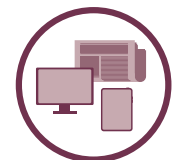

MASS MEDIA
5 FINANGE Where the funding comes from. The best approach is to
increase domestic resources for family planning. Wherer donors need to contribute funds or NOCS are delilivering
darammes there should be a clear exit strategy for

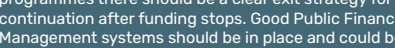




\section{Interventions}

\section{How can quality voluntary family planning programmes best be designed?}

There is an abundance of evidence and best practices in the literature (Quak \& Tul, 2020; Mbizvo \& Phillips, 2014). FP2030 has built the global family planning movement that drives best practice in voluntary family planning, including working with governments and partners to implement costed plans for national programmes. The United Nations Population Fund (UNFPA)

is the lead agency for family planning and should be consulted about advancing family planning in countries. The Family

Planning High Impact Practices also has a fuller list of evidence-based family planning practices (see Resources). This review identified several components that are important for programmes and strategies (Bruce, 1990), particularly when they are embedded in strong national family planning programmes:

\section{- Availability of a choice of methods:}

It is important to meet the different needs

of individuals through the provision of

a full range of contraception methods and quality counselling/information on their use. Also, all methods should be affordable.

- Quality of services and efficient supply of methods: Staff must be technically

competent and respect their clients, including their need for privacy. Facilities should be clean without long waiting times. Quality provision also involves adequate procurement, storage, and transportation systems. Failure to provide the right methods on time could result in distrust in the services and reduces their effectiveness.

- Tailored and integrated adolescents services: Services need to be tailored for different groups, particularly for adolescents. Evidence shows that needs, barriers, and approaches to access and use of contraception by adolescents, especially those who are not married, is different.

- Use of community-based or outreach workers: There is proven evidence of the advantages of using participatory approaches with strong community-level involvement (see case study).

- Use of social marketing: Social

marketing in family planning programmes makes contraceptive products accessible and affordable by including privatesector outlets, such as pharmacies and shops, while using commercial marketing techniques to achieve specific behavioural goals.

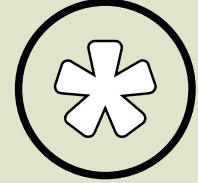

Case study:

\section{Community health workers}

in Zambia

A critical shortage of doctors, nurses and midwives in many sub-Saharan

African countries inhibits efforts to expand access to family planning services, especially in rural areas. One way to fill this gap is for community health workers (CHWs) to provide contraceptives, an intervention for which there is growing evidence and international support. In 2009 . with approval from the Government of Zambia, FHI 360 collaborated with ChildFund Zambia to design and implement training for $\mathrm{CHWs}$ on injectable contraceptives and other methods, as part of its existing $\mathrm{CHW}$ family planning programme (Chin-

Quee et al., 2013). This study shows that CHWs increase safety, feasibility and acceptability of contraceptive methods in communities. The study affirms that the provision of injectable contraceptives by $\mathrm{CHWs}$, as part of a method mix, has very high rates of uptake in hard-to-reach areas. High continuation rates among clients mean that costs of the intervention can be low when added to an existing community-based distribution programme.

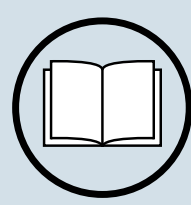

\section{Further readings:}

\section{Male participation}

A Policy Brief published by the Institute for Reproductive Health, Georgetown University (USAID, 2014) examines stimulating men's engagement in family planning programmes.

A working paper published by the Population Council (Hardee et al.

2016) looks at the inclusion of men as contraceptive users.

\section{Resources:}

\section{Best practices for family} planning promotion

\section{- Advance Family Planning (AFP)}

- Family Planning 2020.

- USAID Family Planning High Impact

Practices. 


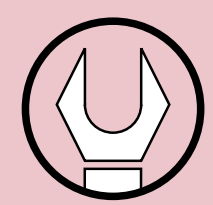

\section{Key guiding questions:}

01. How can girls' education support a fertility transition?

02. What is needed to reduce child, early and forced marriage?

03. What is the link between women's and girls' empowerment and fertility?

04. How important are economic and employment interventions to advance a demographic transition?

\section{Indirect interventions}

\section{How can girls' education support a fertility transition?}

Research shows that girls' education, particularly secondary education, strongly correlates with a decrease in how many children a girl will have. It drives lower actual fertility and also drives lower desired fertility (Pradhan \& Canning, 2015). There are a number of reasons for this:

- Educated women have better knowledge on how to access and use contraception. They also have greater bargaining power to use it. An analysis of DHS data in 30 sub-Saharan African countries found that "education levels are positively associated with demand for and use of contraception and negatively associated with fertility and desired family size" (Bongaarts, 2010). Women with secondary or higher education were found to have, on average, lower fertility than women with no education (3.4 vs 6.3 births per woman). The same was found for desired family size (3.7 vs 5.6 births per woman).

- Increased education and agency need to be complemented by youth-friendly sexual and reproductive health and rights (SRHR) service provision. Among women who want to avoid a pregnancy, unmet need is disproportionately high for adolescents aged 15-19 (43\%), compared with that among all women aged 15-49 (24\%) (Sully et al., 2019).

- An educated woman earns more - one additional year of schooling can increase a woman's lifetime earnings by $10 \%$ in developing countries overall. In subSaharan Africa, this increases to $11.7 \%$
(Psacharopoulos \& Patrinos, 2004). This increases the opportunity cost of having more children, through potential lost earnings. A more educated woman, who earns more, is also likely to have fewer children so she can invest more in the human capital of the children she does have. In this way, the benefits can be intergenerational.

- Girls in school are less likely to be married - girls who have completed secondary education are up to six times less likely to marry as children compared to girls who have little or no education. If every girl went to secondary school, the evidence shows that the prevalence of child marriage would fall by two thirds (see more in UNESCO Girls' Education factsheet). It is difficult to draw causality in either direction though, given the complexity. Early marriage and adolescent pregnancy can be both a cause and a consequence of dropping out of school, and girls who have already dropped out of school are more likely to marry/get pregnant. There are confounding factors at play, such as socioeconomic status, social norms, low school attainment, stigma from getting pregnant - but studies are not able to distinguish one factor from another. However, the earlier a girl marries, the more years she has ahead of her for childbearing. She may face intense social pressure to prove he fertility and has less power to negotiate the use of contraception. In 2013, UNFPA estimated that $90 \%$ of adolescents who give birth are married.
- The child of an educated mother is 50\% more likely to be immunised and live at least to the age of five (International Commission on Financing Global Education Opportunity, 2016). Pregnancy and birth-related complications are also the leading cause of death amongst girls aged 15-19, which could be curbed if more girls stayed in school and delayed pregnancy. Girls' education therefore plays a significant role in reducing child, newborn and maternal mortality, which in turn contributes to the fertility transition.

- For some girls who get pregnant, they will immediately lose their right to get an education, even if they have their family's support to continue. In June 2018, Human Rights Watch found that 24 African countries lack a re-entry policy or law to protect pregnant girls' right to education, which leads to irregular enforcement of compulsory education at the school level. This will have knockon effects on their future earnings, their children's development and likelihood of subsequent pregnancies.

Girls' education requires a multicomponent or "bundled" response to address the multiple challenges that girls face. Initiatives should be child-centred, learner-driven, and equity-targeted.

They should be holistic in their approach, coordinated across sectors and leveraging expertise across health. WASH (including Menstrual Health Management), SRHR, nutrition, and social protection. 


\section{Interventions}

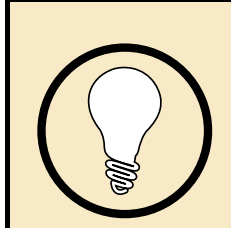

\section{Spotlight: Definitions}

Agency: The definition of agency in the Capability Approach denotes the activities a person can do to realise any of their goals. An individual who has agency means having the ability to make their own choices and control their own lives. Agency is limited by prevailing social structures, including social norms, that set boundaries on individual action. Increased agency and a sense of entitlement is a critical component of girls' empowerment (Sen, 1999; Edmonds et al., 2020).

Empowerment: Brings together an

individual's agency and capability - having the ability to make their own choices and

the environment around them that allows them to do so. Empowerment of girls and women specifically denotes a process

and an outcome where girls and women gain greater power and control over their own lives. It involves awareness-raising. building self-confidence, expansion of choices, increased access to and control over resources and actions to transform the structures and institutions which perpetuate discrimination and inequality (Keleher, 2014 (In French); UN Women, 2002).
Gender equality: The state of being equal in status, rights and opportunities, and of being valued equally, regardless of sex or gender identity and/or expression.

Marginalisation: A form of acute and persistent disadvantage rooted in underlying social inequalities. Sources of disadvantage and discrimination limit an individual's ability to participate in society and access opportunities on an equal basis with others. Given the challenges faced by marginalised groups, it costs more for interventions to reach these individuals.

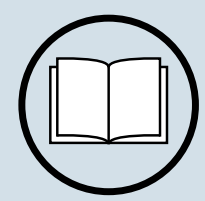

\section{Further reading:}

\section{Effective interventions in secondary education in}

\section{Africa}

- The importance of a specific focus on secondary education is, in particular, relevant in relation to the demographic transition. A report by the MasterCard Foundation

(2020) on effective interventions in secondary education in Africa shows that secondary education can contribute to broad-based economic growth through improved labour productivity. Supporting quality of education is most relevant; for example, by improving curriculum and teacher trainings. Financing must target equity issues and interventions should be part of an education system approach.
Resources:

\section{Linking education} with fertility

Useful resources are: Bongaarts et al., (2017), Kim (2016), Lutz et al., (2019). Shapiro (2017), and Watkins \& Kaler (2016). 


\section{What is needed to reduce}

\section{child, early and forced marriage?}

Some of the complex drivers of child marriage are social norms, gender inequality, poverty, and insecurity. SubSaharan Africa has the highest child marriage rates, particularly in fragile states. The COVID-19 pandemic increases the likelihood of child marriage; UNICEF (2021) predicts that over the next decade up to 10 million more girls will be at risk of becoming child brides as a result of the pandemic.

Several interventions to delay early marriage have been reviewed, and the dominant impression is that most interventions are intense and small with little scope for replication at scale (Walker, 2012; Clark et al., 2017). Malhotra and Elnakib's (2021) review shows that single component interventions are more sustainable than multicomponent interventions. There is also some evidence that consistent laws against marriage before the age of 18 are associated with lower child marriage and teenage fertility (Maswikwa et al., 2015). As such registration of births (birth certification) is helpful because, without it, laws are difficult to enforce. It is important that laws are implemented, with initiatives for enforcement to hold violators to account. According to Plan International, despite continued efforts, over 290 million children under five do not have a birth certificate.

Increased secondary enrolment of girls is the most effective and scalable way of reducing early marriage (Marphatia et al., 2019). A World Bank analysis of data from 18 countries, including 12 in Africa, estimated that each additional year of schooling in secondary education results in a six percentage point reduction of child marriage and teenage childbearing (Wodon et al., 2018). The most effective interventions to address harmful social norms and attitudes work at different levels - with adolescent girls, their male and female parents and caregivers, with men and boys, and with actors with power to influence communities (e.g. traditional leaders, religious leaders, teachers). Media campaigns can also add value when coupled with face-to-face discussion groups. However, it should be considered that the most marginalised people may not have access to all media channels. Furthermore, it is important to identify incentives for individuals, families and communities to change social norms. Social norms approaches that engage with whole communities achieve better results (for more information see here; also Further readings)

However, the effect of a reduction in early marriage as a contributor to fertility decline could be offset by increases in premarital childbearing. Therefore, voluntary family planning promotion for teenagers remains important in any intervention aiming at increasing age of marriage.

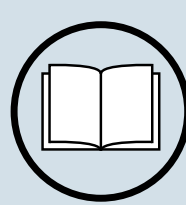

\section{Further reading:}

\section{Birth registration}

Plan International's guidance on Innovations in birth registration.

\section{Resources:}

\section{Women's empowerment}

- What Works to Prevent Violence Against Women and Girls reports.

- Other useful resources are: Upadhyay \& Karasek (2012). Frase et al., (2017), Cleland et al., (2020), Sedgh \& Hussain (2014), and Choiriyyah \& Becker (2018).

\section{What is the link between women's and girls' empowerment and fertility?}

The immediate drivers show that fertility is correlated with the level of empowerment (agency, choice and control) that women and girls have over their bodies and in sexual relationships. These drivers include marriage patterns, birth spacing through abstinence/breastfeeding and/or access to contraceptives, and access to and use of family planning and (safe) abortion services. Women and girls with the least agency, choice and control over these drivers typically have more children and are at most risk of being left behind in the transition).

The intermediate determinants that affect fertility relate to the household, community, institutional and structural level factors. They show that women and girls with the highest fertility and the least agency, choice and control are often those in poor and low-income households; in rural areas: experiencing violence; in child, early or forced marriages; living in communities and societies with restrictive and conservative gender norms; with limited access and uptake of education and health services; who have been displaced; who are excluded from formal labour markets: and where women are excluded from decision-making fora and governance.

These determinants intersect with personal characteristics and factors that may serve to further disadvantage women and girls and put them at higher risk of being left behind. These include disability, age, ethnicity, religion, caste, HIV status, 


\section{Interventions}

sexual orientation, migrant or refugee status, and nationality. Disability and adolescence are always risk factors, while others will be context specific. Women and girls living with disabilities are more likely to experience intimate partner violence (IPV). Child, early and forced marriage all increase the risk of IPV. The greater the age difference between girls and their husbands, the more likely they are to experience IPV. Women and girls living with disabilities are also more likely to be excluded from education and employment and face barriers to accessing basic health services. For example, children living with disabilities made up $15 \%$ of all outof-school children before the pandemic (UNESCO GEM, 2020).

Social norms are at the root of the many barriers to progressing women's and girls' rights - they often place lesser value on women and girls and grant men control over women. Social norms also have a strong impact on voluntary family planning decisions (see Resources). Negative stereotypes and social stigma around contraception limit their uptake. In many relationships, men dominate decision-making. A key reason for not using contraception is opposition by a male partner. Studies from Tanzania (Schuler et al., 2011) and Uganda (Nalwadda et al., 2010) found that using contraception in secret against the wishes of husbands could lead to violence or divorce (see also Further reading). Community attitudes, such as those of parents, faith leaders, teachers and providers, play a role in shaping those views.
Empowering women and girls and promoting gender equality is vital to realising a demographic transition. To make this inclusive, it is necessary to reach the poorest, the girls most likely to drop out of school, those at greatest risk of being married early, and the girls and young women who face the biggest barriers to entering productive livelihoods. Tackling harmful social norms that perpetuate gender inequality remains key to ensuring girls and women influence decisions that affect their lives and in turn go on to contribute fully to their household or economy

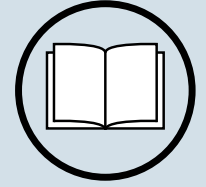

04. How important are economic and employment interventions to advance a demographic transition?

In general, economic growth and subsequent increases in income are not an important precondition for fertility decline. There are many accounts of countries that have managed voluntary fertility decline in their early development stages (e.g. Bangladesh, South India, Kenya). More important is that women have increased opportunities to participate in decent work in labour markets. Most women in sub-Saharan Africa combine unpaid care for children with informal and low productive work in agriculture or family enterprises. Large family sizes reduce their productive labour years significantly, estimated at a reduction of 1.9 years of productive

\section{Further reading:}

\section{Reaching the most vulnerable}

\section{OECD Social Institutions and Gender
Index (SIGI) country profiles include}

indicators and analysis from four areas: (1) discrimination in the family; (2) restricted physical integrity: (3) restricted access to productive and financial resources; and (4) restricted civil liberties.

\section{Resources: Guidance on addressing social norms}

- The Service Communication

Implementation Kit (includes guidance on identifying and addressing relevant social norms).

- The Circle of Care Model and its implementation guidance.

- The LSHTM's ABCD approach or University College London's COM-B Model.

- Johns Hopkins University Center for Communications Programs (JHU-CCP) Pathways Models.

participation per woman for each child (Bloom et al., 2009). This complicates their move into more productive work. However, when female labour market participation can be promoted combined with gains in income and job security, reductions in fertility could be achieved. Again, this depends mostly on girls' education and promotion of voluntary family planning, in combination with providing young women access to labour markets after schooling. As such, the literature mostly highlights the importance of an accelerated demographic transition (e.g. through family planning and girls' education) as a trigger for productivity gains, higher participation rate of women in the labour force, increased incomes, and betterquality jobs. This will only happen when fertility induced increases in GNP per capita are (at least partially) reinvested in the human capital of future workers.

\section{Resources:}

\section{Linking fertility with labour} markets and economic growth

Useful resources are: Canning et al.

(2015), Karra et al., (2017), Lee et al.

(2020), Mason et al., (2016), and Quak (2021). 


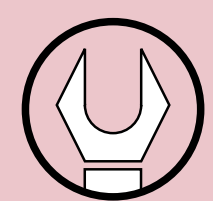

Key guiding questions:

01 . What is a multisectoral approach?

02. What are the key challenges for establishing effective multisectoral approaches?

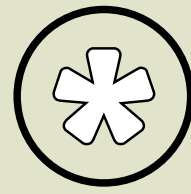

Case study: Providing family planning services in Uganda

In Uganda, the government has

recognised that increasing uptake of

family planning services requires a

multisectoral approach. The Uganda

Family Planning Costed Implementation

Plan mainstreams family planning policy,

interventions, and delivery of services

in multisectoral domains with the aim to

spur social and economic transformation.

The Plan emphasises the need for all

family planning programmes to engage

with other sectors and stakeholders who

may influence both the quality of and

the demand for services (Muribu, 2020).

The USAID-funded project "Advancing

Partners \& Communities", led by FHI 360 ,

implemented a multisectoral approach by

providing family planning services in high-

Taking a multisectoral approach to accelerating a demographic transition

\section{What is a multisectoral} approach?

Three categories of multisectoral approach can be distinguished. Firstly, a narrow approach that focuses on linking family planning services with community-based initiatives (e.g. empowerment, social norms) and connecting with multiple local stakeholders (see Uganda case study). Secondly, there are multisectoral approaches

fertility districts in Uganda. It started by exploring social norms to identify factors that drive high fertility, teenage pregnancy, and low contraceptive use. Given the multidimensional nature of the factors, the project applied a multisectoral approach at the district level to build ownership across all relevant sectors and stakeholders.

District multisectoral working groups were formed - including, for example, farmers' groups and school managers - and they identified ways to address needs and barriers. Furthermore, investments were made to improve the service provision. Funding for meetings of multisectoral groups could continue beyond the project through engagement with communitybased organisations or through district health offices that included such meetings in their budget.

Source: Muribu (2020) that integrate direct and indirect interventions, which could include, for instance, family planning, education, health care, and women's empowerment (see Spotlight box). Thirdly, voluntary family planning can be integrated within other types of programme (e.g. programmes focused on prosperity, humanitarian assistance, environment, etc.).

The aim of multisectoral approaches is often to introduce new, integrated services

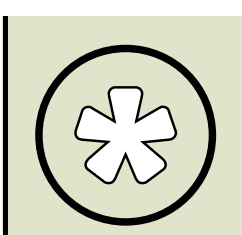

Case study:

\section{The Danida approach}

Danida has placed sexual and reproductive health and rights (SRHR) of women and girls at the centre of its international work and priorities. The World 2030: Denmark's strategy for development cooperation and humanitarian action (Danida, 2017) recognises the need "to reverse the global population trend and turn the development around from being a challenge and a potential threat to being an opportunity and a resource". In 2020, Denmark allocated USD 120 million to global efforts for SRHR, including those focusing on women and girls in humanitarian crises and conflicts. As part of this contribution, Danida initiated cooperation with the Population Council in 2020 with a focus on population growth, youth, and climate change. The Population and/or increase the effectiveness of these services over a sustained period. Multisectoral approaches can mobilise multisectoral stakeholders, widen the outreach to different population groups, break down silos and bring in an integrated team structure. Taking a multisectoral approach can also have a far greater impact - with important "multiplier effects" - than the sum of single interventions.

Council's programme Contributing to the Sustainable Development Goals by Investing in Adolescent Girls and Young Women (AGYW) runs from July 2020 to December 2022, with a focus on girls in sub-Saharan Africa. The Population Council will undertake a body of interdisciplinary research to deliver three complementary outputs that together will: (a) increase understanding of the population, health, development, economic, and environmental impacts of more widespread and intentional investments in AGYW; (b) equip national and global decision makers with the right evidence to guide investments; and (c) address the evidence gaps in climate and population research. Key outputs include development of an evidencebased framework outlining opportunities on how to optimise adolescents' transitions to adulthood in order to accelerate progress for adolescents, their families, and communities, including the influence of education and family planning on fertility rates.

Source: Price (2020) 


\section{Multisectoral approaches}

02. What are the key challenges for establishing effective multisectoral approaches?

The World Health Organization (WHO) which is strongly in favour of multisectoral approaches in family planning programmes, mentions several barriers for integrated action. These include political will or commitment, lack of resources and coordination, and entrenched siloed thinking. Programmes should focus on addressing these barriers; for example. by providing political, religious, and cultural leaders with information about the importance of family planning (in combination with information on girls' education and women's empowerment) and building the capacity of programme managers to coordinate and structure multisectoral approaches. Multisectoral approaches need to be systematic and carefully designed, by understanding conflicting interests among sectors, power imbalances, and competition for resources. Ownership of such programmes and specific responsibilities for all stakeholders must be clear. Integrated, multisector programming tends to be more time intensive than single-sector programming. Collaborating with a large group of stakeholders requires frequent meetings and communication, which should be adequately planned and budgeted for.

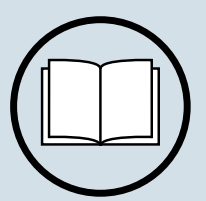

Further reading:

Barriers and opportunities of multisectoral approaches

The report of the Johns Hopkins Center for Communication Programs

(2019) study conducted for USAID on integrated approaches of family planning with other development sectors is useful reading. The study looked in particular at projects that aim for social and behavioural change. The report gives a good overview of barriers and opportunities of multisectoral approaches. It shows that multiple tools are needed for multiple audiences (e.g. donors, implementing partners, governments, etc.) and these tools require input from all involved actors and sectors. Furthermore, the report points to extra investments at the outset to build capacity of people or organisations that are less advanced in the knowledge of family planning programming, mostly non-health sectors. Such vertical programming in building capacity lays the groundwork for multisectoral integration.

\section{5}

Case study:

\section{Norway's approach to include} family planning in climate

\section{change programmes}

Launched in 2015, the Central African

Forest Initiative (CAFI) supports strategic, holistic and country-level REDD+ and

Low Emission Development investments, focusing on Central African high-forest cover countries (Cameroon, the Central African Republic, DRC, Equatoria

Guinea, Gabon, and Republic of Congo).

Since 2012, DRC has established a REDD+ National Fund (French acronym

FONAREDD). CAFI funds have capitalised FONAREDD and are channelled through it. To date, 16 programmes have been approved, totalling over USD 140 million of CAFI capital. Five of the CAFI/FONAREDD-

funded provincial integrated programmes, covering eight provinces, have integrated demography activities and targets over the next five years aimed at reducing demographic pressure on forests. This includes a specific programme on Scaling up family planning (French acronym, PROMIS-PF), running from 2019 to 2022 (potentially extending to 2025). PROMIS-PF is implemented by Tulane University, Marie Stopes International, and DKT International with supplies from UNFPA and the United Nations Office for Project Services (UNOPS), and is funded by CAFI (USD 8 million) and Norway (USD 25 million). It aims to reduce the effects of unplanned demographic growth on forests, supporting 193 health centres and 8 Million Couple Years of Protection, and also increase by $1.5 \%$ each year the services and inputs (such as contraceptives) in the eight provinces covered by REDD+ integrated programmes.

Source: Price (2020) 


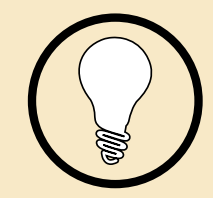

Spotlight:

\section{Integrating family planning with health, education, and labour market programmes}

\section{Health systems:}

- In sub-Saharan Africa, most family planning services are located within health facilities, but effective integration is often lacking. Evidence shows that family planning services provided during the postpartum period (Cleland et al., 2015), as well as child immunisation, is very effective (e.g. see Hamdallah et al., 2017). Support is needed to establish well-functioning referral systems to family planning services within health-care systems, also related to HIV (Warren et al., 2017 Mayhew et al., 2020). If not, the reality is that most of these opportunities are missed, as have been shown by evidence from Senegal and Uganda (Malacher \& Polis, 2014).
- Health systems are not linear, which means that they are unpredictable and adapting one segment has consequences for the rest of the system. Including family planning service delivery within a health system requires a comprehensive approach and awareness of tradeoffs. For more information see the K4D Learning Journey on Health Systems Strengthening webpage.

- Integrated services of existing health contact points with women and men are a step forward, but there is the need for a health systems perspective in realising this. This includes health systems hardware (supplies, financing, guidelines) and software (values, human resources) as well as careful monitoring and assessment of trade-offs and adjustments made (such as additional service time quality of services, integrated reporting oversight, etc.). Despite repeated calls by the WHO and the World Bank for universal access to quality primary health care, fragile and under-staffed health systems in many sub-Saharan African countries remain a severe constraint on the availability of contraceptive services.

\section{Education systems:}

- The obvious way of integrating family planning information in education systems is by offering comprehensive sexuality education within the curriculum (Vanwesenbeeck et al., 2016), to help prevent early pregnancy. Secondary schools need staff that have been trained well to provide sexuality education.
- At secondary schools (and in higher education), family planning counselling would be desirable. As well as measures to prevent early pregnancy, initiatives should also be targeted at supporting girls to stay in school when pregnant and after they have children.

Girls Education Challenge (GEC) Promoting Equality in African Schools (PEAS) project supports young mothers in Uganda and Zambia to go back to school, and as such gives them an opportunity to regain contro of their lives. PEAS directly supports and monitors its schools through inspections and audits and offers professional development for all its teachers and schoo staff, including on SRHR.

- The Sisters for Sisters programme in Nepal supports menstrual hygiene management water sanitation and hygiene (WASH), and girls' education for marginalised groups. Female mentors offer encouragement accountability and essential information on sexual and reproductive health issues and checking in with the girls and motivating them to keep up with their learning.

- Support from civil society organisations could be useful as a strategy to increase acceptance of sexuality education by parents or guardians of the pupils. Advocacy should highlight the importance of education and counselling in schools to lowering the number of teenage pregnancies and improving the reproductive health of youth, starting at the high level of health and education ministries and at implementation or project level with district health and education officers.
Women's participation in labour markets:

- Some evidence shows that inclusion of sexuality education in vocational trainings and explicitly targeting for better employment expectations through trainings both improve contraceptive use (USAID, 2017).

- Cash transfers are only effective for the promotion of contraceptive methods if interventions are targeted at specific vulnerable youth groups who have limited access to financial resources (aged 15-24), such as female orphans (Handa et al., 2015).

- Microfinance has no direct link with contraceptive use, but women's savings groups often include trainings in health and hygiene, which also could include awareness about family planning (USAID, 2017).

- For broader impact, support might be more effective by encouraging betterquality and higher paid jobs for women as a way to raise the opportunity costs of childbearing. More attention could be given to combine this with family planning promotion. 


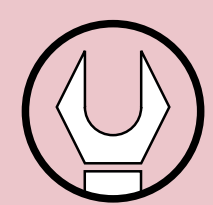

Key guiding questions:

01 . What is the benefit of applying a demographic lens to programmes and policy?

02. What is the relationship between demographic factors and poverty?

03. Should demographic factors be considered as endogenous or exogenous?

04. What types of development programme could benefit from a demographic lens?

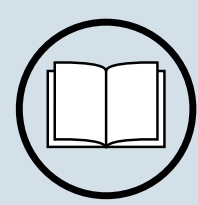

Resources:

\section{Linking demography} and poverty

Useful resources are: Ahlburg \& Cassen (2008), Merrick (2002), Sinding (2009),

UNFPA (2012), and

Wietzke (2020).

Sectoral entry points for mainstreaming population dynamics

01. What is the benefit of applying a demographic lens to programmes and policy? Better understanding of population dynamics is relevant for every development professional. The growth, distribution and composition of populations can impact a programme's success, particularly in terms of economic and human development, sustainability and inclusiveness. A key feature of most demographic data (censuses, surveys), unlike many other data sources, is that they represent entire populations. This makes them invaluable in providing overall assessments of

\section{What is the relationship between demographic factors \\ and poverty?}

Development programmes aim to reduce poverty and reduce inequalities. Demographic factors affect poverty levels and inequality within and among countries in fundamental ways (UNFPA, 2012; Wietzke, 2020). At the micro level, fertility and mortality rates affect household economic wellbeing (in nearly all countries, a strong correlation exists between number of children and household poverty); at the macro level, the "demographic dividend" associated with the transition from a majority youth population to a large productive-age population affects a country's GDP per capita and economic growth rates. population characteristics and how these vary geographically and in other dimensions. Repeated over time, they chart progress in human welfare (survival, nutrition, education, etc.) (see section A). Applying a demographic lens to development planning can help ensure that:

- Services remain available and relevant to target groups in the medium-to-longer term and can adapt to changing needs brought about by population dynamics; for example, changing burden of disease, changing education levels of the population, and changing transport and infrastructure needs.

- Services are proportionate (i.e. enough services to meet increased demand, such as teacher to pupil, or health worker to patient ratios).

- Services are adequately resourced (bearing in mind the longer-term trajectory of population growth and the need to train a sufficient workforce in education, health, etc.).

As a first step, it can be useful to undertake a demographic diagnostic (i.e. combining available data, projections and qualitative analysis) to feed into programme design.

Many sub-Saharan African countries experience a high fertility-poverty trap, in which low incomes may exacerbate high fertility rates and vice versa (Wietzke. 2020). Although high fertility is a common element among them, this does not mean that poverty and low life expectancy traps are only associated with high fertility or create high fertility. The way out of this trap involves economic, education and health policies, while making voluntary family planning services available (see sections $C$ and D).

\section{Should demographic factors} be considered as endogenous or

\section{exogenous?}

In traditional development planning,

population factors are considered exogenous to the planning process. This means that population projections are mainly used for the projection of per capita growth rates, future labour force supply, food security. and the demand for schooling and health services. However, looking through a demographic lens to development involves more than just projecting population growth rates. It should investigate explicit links between population factors and socioeconomic changes. For instance increases in secondary school enrolments of girls will lead to lower fertility and mortality (see section D); or, a better understanding of 
inequalities between population subgroups; or, understand morbidity or mortality across economic classes of the population (see case study on COVID-19 responses).

Demography is not only relevant for development planning, but also for the monitoring and evaluation of programmes, in areas such as education, health and economic development. Donor programmes are often evaluated by "value for money"; for example, by looking at the numbers of people served with limited resources. But a more thorough evaluation might measure changes in the proportion of specific groups served by these programmes. Development programmes could be evaluated by examining the socioeconomic characteristics of the population before, during and after the initiation of a project.

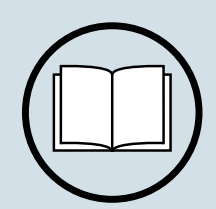

\section{Further reading}

- For more information on the links between climate and demography, see evidence review by Price (2020).

- For more information on the links between conflict and governance and demography, see evidence review by O'Driscoll (2020).

- For more information on the links between labour markets and demography, see evidence review by Quak (2021).

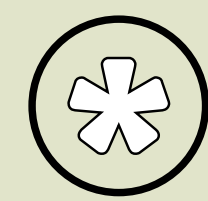

\section{Case study: Importance of} demography in COVID-19

\section{responses and recovery}

The importance of demographic

indicators in relation to mortality became evident during the COVID-19 pandemic,

particularly to identify groups in society that are more at risk of developing severe symptoms (e.g. sex, age, socioeconomic status, ethnicity, urban vs rural). It is important to understand how these demographic indicators interact with other components, including lifestyle (such as school, work, commuting, local facilities including public facilities like toilets, water source) and community contact as well as the frequency and degree of social mixing (how intergenerational and how this varies across age groups). Demographics need to be incorporated into assumptions and planning; for example, regarding vaccines - including factors directly linked to vaccines (e.g. how and when vaccination happens, ultimate impact on transmission/disease) and non-vaccine factors (e.g. overall direct health impact, base transmission). Both also affect assumptions on spread and variants, public health response, etc. Demographics also need to be incorporated (or at least acknowledged) in the non-epidemiology COVID-19 scenarios, such as in economics and urban planning, and all recovery responses.

\section{What types of development programme could benefit from a demographic lens?}

- Food systems: Agricultural or food

system programmes need to understand changing demand, which depends in part on demographic factors such as population growth, age structures and urbanisation, alongside land use, consumption patterns, etc. Population data and analysis should be used in programme design and evaluations, as well as to identify risks and opportunities related to changes in the food system (Woodhill \& Quak, 2019).

\section{- Environment and climate change:} Rapid population growth may exacerbate local environmental problems through over-grazing and deforestation. Climate change and environment programmes should consider demography beyond population growth, as estimates of how different groups contribute to and are at risk from climate change or environmental degradation are equally important.

- Conflict and governance: Rapid population growth is linked to limited opportunities for specific groups of youth to move from education to jobs to higher consumption, which has implications for the probability of conflict or forms of instability. Therefore, applying a demographic lens can be useful for informing conflict or governance programmes.
- Private sector: Rapid population growth is likely to affect the ability of entrants to the labour market to get productive jobs. The need for private sector development programmes to create more (and better) jobs is important in the context of subSaharan Africa, and should be informed by demographic analysis.

- Human development: Sections $C$ and $D$ on interventions and multisectoral approaches highlighted the importance of the link between the demographic transition and education, particularly girls' education. The same is true for health-care systems. Health care is important to reduce mortality rates, particularly infant mortality, which is a key driver of demographic transition and can play an important role in improving access to and quality of family planning. Finance for health care and education, capacity of the health and education systems, and access and quality of the services provided all depend on demographic indicators, which need to be understood in order to understand progress and who benefits and who does not. 


\section{Diplomacy}

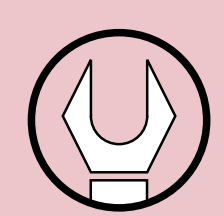

\section{Key guiding questions:}

01. What are the key sensitivities?

02 . Why is the historical context important?

03 . How can the context be best understood?

\section{Language and sensitivities related to demography and population}

\section{What are the key}

\section{sensitivities?}

- The wrong messages can damage efforts to support women's and girls' empowerment and can risk undermining the global effort to improve SRHR. Fertility decisions can also be closely intertwined with cultural practices or religious beliefs. It is imperative to take a rights-based approach, stressing the importance of a woman's own choices. When talking about population or demography, awareness of and sensitivity to the history and politics surrounding these issues needs to be held in mind. Historically, family planning policies and interventions have in some contexts been used in a coercive manner either to limit or to increase the population of whole countries or specific communities for political reasons. The 1994 International Conference on Population and Development (ICPD) in Cairo established a global consensus on the centrality of a rights-based approach to population policies, with women's empowerment and bodily autonomy as the guiding principle. Macro, target-driven approaches to population policy were generally seen as incompatible with this principle. This rights-based consensus remains at the centre of international family planning policy today.

- Fertility decisions can also be closely intertwined with cultural practices or religious beliefs. It is imperative to take a rights-based approach. Specifically, when talking about population and family planning, donors should always stress the importance of women's own choices, refer to "rights-based family planning" or "voluntary family planning".

- Making connections between population growth and climate change can also be controversial. A key sensitivity is that voluntary family planning programmes are largely aimed at high-fertility low- and middle-income countries, which have relatively low per capita emissions, while the high-income countries primarily responsible for causing the climate to change continue their excessive emission of greenhouse gases (Bongaarts \& O'Neill, 2018). Donors should adopt a human rights-based approach (i.e. for women everywhere to have the right to freely choose when and how often to get pregnant) with climate and reproductive justice at the centre. Any impact on climate change or biodiversity/nature is a secondary benefit of voluntary family planning programmes and not the aim of these interventions.

- Failing to take account of such sensitivities could cause inadvertent harm and risk - A backlash from within some countries, where family planning is framed by the opposition as a Western or imperialist agenda to limit (non-white) populations. This opposition is small, but could be strengthened.

- A backlash from those opposed to women's rights, using any indication of a lack of voluntarism as a hook: and

- A backlash from women's rights' organisations, due to concerns that approaches to family planning are overtly or subtly coercive and do not offer full, free, and informed choice to women.

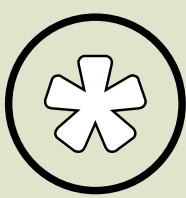

\section{Case study:}

\section{African Union roadmap}

The African Union designated

2017 as the year of Harnessing the Demographic Dividend through Investments in Youth, and produced a roadmap to do so. Achieving a demographic dividend requires an accelerated demographic transition. The language used in the roadmap emphasises a broader development approach, and avoids putting too much emphasis on family planning promotion. The roadmap is based on four interconnected pillars that are critical to increasing investments in youth, driving change, and setting African countries on the path towards reaping the benefits of the demographic dividend. The first pillar is "Employment and Entrepreneurship", the second is "Education and Skills Development", the third is "Health and Wellbeing", and the fourth pillar is "Rights, Governance and Youth Empowerment". Family planning is part of the health and wellbeing pillar but is also to be embedded within a broader strategy of good governance, empowerment, education, and employment.

Source: African Union Commission (2017). 


\section{Diplomacy}

\section{Why is the historical context}

\section{important?}

- When talking about population or

demography, awareness of and sensitivity to the history and politics surrounding these issues needs to be held in mind. Historically, family planning policies and interventions have in some contexts been used in a coercive manner either to limit or to increase the population of whole countries or specific communities for political reasons.

- The second half of the 20th century saw a global focus on population control and a target-driven approach to reducing fertility rates, partly motivated by concerns that rapid global population growth was unsustainable and threatened living standards and the environment. The US was a major funder of family planning efforts during this period, through government funding, philanthropic trusts such as the Ford Foundation, and the establishment of multilateral bodies such as UNFPA. This period was also marred by coercive family planning policies, famously the one-child policy in China (1979) and forced sterilisation in India during The Emergency (1976-77), which contributed to an association between population policies and human rights abuses.
- The 1994 International Conference on Population and Development (ICPD) in Cairo established a global consensus on the centrality of a rights-based approach to population policies, with women's empowerment and bodily autonomy as the guiding principle. Macro, target-driven approaches to population policy were generally seen as incompatible with this principle. This rights-based consensus remains at the centre of international family planning policy today.

\section{How can the context be}

\section{best understood?}

Any argument made in political dialogues (positive or negative) that is related to population dynamics needs to be rooted in robust country-specific evidence. This will help identify and understand sensitivities and challenges as early as possible. There are several ways to understand and recognise sensitivities and challenges within specific countries:

- A key source of information is to look at how traditional media report on sensitive issues, such as the use of modern contraceptives, child marriage, women's empowerment, rapid population growth, etc.

- Digital platforms - Facebook, Twitter, and local chat apps - can be used as a tool to understand local sensitivities and discussions on these topics. Digital platforms are a good way to draw lines between different groups in society and their views on such issues.

- Talking with local NGOs or other

advocates and champions working on SRHR is a good entry point to interpret the local situation. However, some research is needed to know the organisations better in order to understand their position and biases.
- Liaise with development partners in the country to exchange experiences. Donors (multilateral, donor countries, international NGOs) have their own programmes and priorities, but cooperation and sharing experiences is important for both sides.

\section{- Seek alternative entry points to the} local debate to identify local stakeholders for each driver of the demographic transition or look at investment programmes in youth. 


\section{Engaging with Stakeholders}

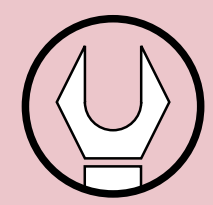

Key guiding questions:

1. In what circumstances would it be better to engage with local partners or other stakeholders for policy dialogues and influencing?

2. What local stakeholders are best suited for advocacy work?

3. How can engagement with local stakeholders take shape?

4. Why can coalitions be an effective tool for policy influencing?

5. What approaches can be used to build coalitions for advocacy work?

6. How can progress and results be monitored?
Engaging with partners and local stakeholders for policy reform

01. In what circumstances would it be better to engage with local partners or other stakeholders for policy dialogues and influencing?

- Where ownership is central to making progress, particularly where the issue is sensitive and good entry points at government level are missing.

- When opposing interest groups make assertive attempts to flag technical assistance as international interference in their campaigns (e.g. against comprehensive sexual education or voluntary family planning), advocacy could be led by civil society rather than international partners.

- Even if there are good entry points for soft power and a trusted relationship, it is helpful to engage with local partners and support coalitions of trusted organisations on specific advocacy topics (including family planning promotion, girls' education, and women's empowerment).
02. What local stakeholders are best suited for advocacy work?

- Working through partners that are seen to be more neutral, such as UN agencies (e.g. UNFPA) or African-led organisations (e.g. the African Institute for Development Policy (AFIDEP), African Union) under the auspices of bilateral programmes, can be useful in policy influencing (e.g. getting information to the right persons).

- Local NGOs and civil society know local sensitivities, have networks with grassroots groups to identify problems and collect evidence, have contacts with the local media, and often have access to supportive local and national politicians. - Academics or other experts can play a key role in improving the evidence base or quality checks on problems, solutions, and concepts. Local stakeholders could also be a vehicle to take up academic research, such as inviting experts to round-table policy discussions or using their findings in policy briefings.

- Certain professional organisations (e.g. medical associations or pharmacists in the private sector) are important stakeholders as their membership holds a wealth of information in their fields of expertise.
03. How can engagement with local stakeholders take shape?

- A political economy analysis combined with a stakeholder analysis is important. These should be updated over time because political moods and interests change; for example, they are affected by elections. Based on such analysis, it can be decided to pause engagement with a stakeholder, intensify engagement or broaden the engagement in a coalition.

- Take advantage of opportunities and be aware of changing risks. A new National Development Plan or an important conference that takes place in the country can give momentum to bringing attention to specific topics (e.g. girls' education) on which new relationships can be built. However, with new opportunities come new risks.

- Build consensus for change through technical engagement. For example, in Zambia considerable progress was made on safe abortion using technical working groups which rolled out guidance down to facility level without the aid of national launches (see case study).

- Build on less sensitive work as an entry point. For example, studies or events related to youth employment, quality of education, and community health workers can be used as a platform to start broader discussions on the demographic transition. 


\section{Engaging with Stakeholders}

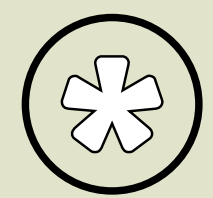

Case study: Zambia's coalition to adopt standards and guidelines for comprehensive abortion care

The coalition to adopt standards and guidance for comprehensive abortion care in Zambia was successful because of its broad membership and focus at the technical level, which allowed consensus to be reached more easily. The branding of the coalition was also successful as it did not impose strict titles, allowing coalition members to freely adapt messages to their memberships. Some organisations were completely pro-safe abortion, such as Marie Stopes Zambia, IPAS Zambia, and the Planned Parenthood Association of Zambia (PPAZ). Others presented a range of views among their membership - for example, the Zambia Medical Association and the Ministry of Health - but under a pro-safe abortion leadership. Other organisations, such as the WHO and UNPFA, could be considered as "neutral". The availability of financial resources was also crucial.

Evidence-based approaches were important to change some resistance from opposing organisations (e.g. faith organisations and political opposition parties), particularly on tolerance and openness about abortion in cases where a woman's life is at risk. Active monitoring of the situation allowed the coalition to work around threats and to seize opportunities. For example, Panos Institute Southern Africa monitored and tracked media stories; the Ministry of Health provided insider information concerning government developments on safe abortion; and coalition members participated in events held by pro-life organisations to obtain information about their arguments and courses of action, rather than to influence them. The coalition made careful use of language to avoid backlash, to overcome resistance from different groups, and to bring stakeholders together. For instance, the title of the 2018 guidelines uses the word "comprehensive" to reflect the content that includes prevention and aftercare. The message of "leaving no one behind" from the SDGs was also employed.

Source: WYG International (2019).

\section{4 . Why can coalitions be an effective tool for policy influencing?}

There are several approaches to understand how influencing works. One that is often used is John Kingdon's Multiple Stream Approach (MSA), which emphasises that influencing policymakers requires continued, flexible but strategic processes that happen behind the scenes (Kingdon, 1984). The MSA approach is composed of three elements or "streams":

- Problem stream. Policymakers are

interested at any given moment in time to understand problems (e.g. impactful events, important changes, feedback on current policy), but many actors compete to gain the attention of policymakers.

- Policy stream. Solutions to the problems (which can be future problems) are often discussed by communities of practice or experts and need a thorough process of making them acceptable (e.g. evidence, cost calculations, values).

- Politics stream. Proposed solutions can find resistance by interest groups, which often have their own policy influence strategy in place. For change to happen, wider acceptance outside government is needed. 


\section{Engaging with Stakeholders}

Coalition building is one of the strategies used to increase influence and navigate resistance by using coalition partners' expertise and networks; for example, to mobilise groups, to collect evidence, and to seek broad media attention. Such coalitions are groups of organisations or institutions with a common goal (e.g. policy change) through coordinated actions. Within a coalition, organisations are able to seek attention of policymakers for specific problems, find comprehensive and acceptable solutions to solve the problem. and use the strength of the coalition to make their point (Zahariadis, 2016). Donors can be actively involved as members of certain coalitions or can support the coalition.

\section{What approaches can be used to build local coalitions for advocacy work?}

There are many ways in which coalitions are formed. Using CommGAP's stages of building coalitions, in which trust and leveraging diversity are key elements, the following stages can be identified (Cabanero-Verzosa \& Garcia, 2011, p. 345): - Issue identification and specification. This is where the overall objective of the problem is articulated and broken down for detailed analysis, and policy options are defined in terms of a continuum of options (from minimum to maximum reform positions). Communication efforts should focus on gauging public opinion and consulting with policy experts to determine the national mood.
- Relationship/stakeholder mapping. Actors are identified, positions regarding key and related issues are plotted. especially in terms of the policy

options identified in the previous step. Communication efforts focus on listening to actors and key informants.

- Forming core membership. The core of a coalition is convinced about and becomes self-aware of the benefits of change and with leaders and champions identified, the joint agenda takes shape. Communication efforts focus on lobbying and persuasion of influential individuals and key targets, as well as deepening understanding of their positions and trade-offs.

- Demonstrating credibility. The coalition demonstrates that it is knowledgeable about relevant issues, can act effectively, and is worthy of support from stakeholders. Communication focuses on successes and clear evidence from some case studies, framed as much as possible in terms of the interests and incentives of the core membership and key stakeholders.

- Purposeful expansion. It is critical for a small core coalition to build a broader social and resource base while retaining coherence and effectiveness. The target of communication efforts should shift towards addressing the interests of broader relevant issue and policy networks.

- Sustainable transformation. Coalitions could stop here, but others will maintain and often expand the scope of their advocacy work on more fronts, drawing strength from many sources. Communication efforts, therefore, broaden and include appeals to the general public, especially in terms of addressing social norms.

\section{How can progress and results be monitored?}

Soft power, engagement with partners or local stakeholders and coalition building all need monitoring approaches to track progress. A formal monitoring framework with targets and indicators (including who to influence, at what stage, with what purpose and with what expected outcomes) is a helpful tool. However, such frameworks should be flexible in spotting changes in context and responding to new opportunities and risks. When working together in a coalition, it could work to give specific partners in the coalition responsibilities for monitoring, according to their areas of expertise and their networking opportunities (e.g. one organisation oversees media monitoring). A communication strategy with partners within or outside coalitions is important. with frequent pre-set meetings to update each other on developments based on monitoring data, while using digital tools to keep each other updated in between meetings on specific events. opportunities, and risks.

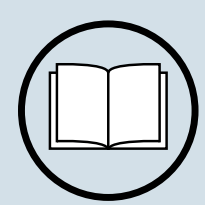

Further reading

Based on the work of the

Communication for Governance \& Accountability Program (CommGAP). People, politics and change: Building communication capacity for governance reform

(Cabanero-Verzosa \& Garcia, 2011 p. 345) extensively looks at practica guidance on how communication approaches can help reformers build understanding and support for their goals and aspirations with the aim to achieve governance reform. It has different modules with practical briefs and highlights several case studies. With a practical approach it explains how to use political economy analysis, secure political commitment and will, mobilise public will, implement coalition building, and manage conflicts among multiple stakeholders. 
- African Union Commission. (2017). AU roadmap on Harnessing the Demographic Dividend through Investments in Youth. https://wcaro. unfpa.org/sites/default/files/pub-pdf/AU\%20 2017\%20DD\%20ROADMAP\%2OFinal\%20-\%20 EN.pdf

- Ahlburg, D. \& Cassen, R. (2008). Population and development. In A. K. Dutt \& J. Ros (Eds.), International handbook of development economics. Cheltenham, UK: Edward Elgar (pp. 316-327). http://eprints.Ise.ac.uk/32511/

- Ajayi, A. \& Kekovole, J. (1998). Kenya's population policy: From apathy to effectiveness. In A. Jain (Ed.), Do population policies matter? (Chapter 4). New York NY: Population Council. https://knowledgecommons.popcouncil.org/ departments_sbsr-rh/983/

- Bloom, D. E., Canning, D., Fink, G. \& Finlay, J. E. (2009). Fertility, female labor force participation, and the demographic dividend. Journal of Economic Growth, 14(2), 79-101. https://link. springer.com/article/10.1007/s10887-0099039-9

- Bongaarts, J. (2010). The causes of educational differences in fertility in sub-Saharan Africa. Vienna Yearbook of Population Research, Volume 8, Education and demography (pp. 31-50). https://www.jstor.org/stable/23025509

- Bongaarts, J. \& O'Neill, B. C. (2018). Global warming policy: Is population left out in the cold? Science 361(6403), 652. https://science. sciencemag.org/content/361/6403/650

- Bongaarts, J., Mensch, B.S. \& Blanc, A. K. (2017). Trends in the age at reproductive transitions in the developing world: The role of education. Population Studies, 71(2), 139-54. https://www. tandfonline.com/doi/full/10.1080/00324728.2 17.1291986

- Bongaarts, J., Gragnolati, M., Ahmed, A. S. \& Corker, J. (2020). Population, development, and policy. New York NY: Population Council. https://knowledgecommons.popcouncil.org/ departments_sbsr-pgy/1141/
- Bruce, J. (1990). Fundamental elements of quality of care: A simple framework. Studies in Family Planning, 21(2), 61-91. https://pubmed. ncbi.nlm.nih.gov/2191476/

- Cabanero-Verzosa, C. \& Garcia, H. R. (2011). People, politics and change: Building communication capacity for governance reform (Technical Brief on Coalition Building). World Bank \& Communication for Governance \& Accountability Program (CommGAP). https://assets.publishing.service.gov.uk/ media/57a08ac140f0b652dd0008ac/ PPCOnline.pdf

- Canning, D., Raja, S. \& Yazbeck, A. S. (2015). Africa's demographic transition: Dividend or disaster? Africa Development Forum, World Bank. http://hdl.handle.net/10986/22036

- Chin-Quee, Bratt. J. Malkin. M. Nduna. M. M. Otterness, C., Jumbe, L. \& Mbewe, R. K. (2013) Building on safety, feasibility, and acceptability: The impact and cost of community health worker provision of injectable contraception. Global Health: Science and Practice, 1(3). https:// doi.org/10.9745/GHSP-D-13-00025

- Choiriyyah, I. \& Becker, S. (2018). Measuring women's covert use of modern contraception in cross-sectional surveys. Studies in Family Planning, 49(2), 143-158. https://pubmed.ncb. nlm.nih.gov/29845621/

- Clark, S., Koski, A. \& Smith-Greenaway, E. (2017). Recent trends in premarital fertility across sub-Saharan Africa. Studies in Family Planning 48(1), 3-22. https://pubmed.ncbi.nlm.nih. gov/28134987/

- Cleland, J. \& Potter, J. E. (2019). Fertility regulation. In D. L. Poston Jr. (Ed.), Handbook of population, 793-817. Cham.: Springer. https:// doi.org/10.1007/978-3-030-10910-3
- Cleland, J., Machiyama, K. \& Casterline, J. B. 2020). Fertility preferences and subsequent childbearing in Africa and Asia: A synthesis of evidence from longitudinal studies in 28 populations. Population Studies 74(1), 1-21. https://pubmed.ncbi.nIm.nih.gov/31694465/

- Cleland, J., Shah, I. H. \& Daniele, M. (2015). Interventions to improve postpartum family planning in low- and middle-income countries: Program implications and research priorities. Studies in Family Planning, 46(4), 423-441. https://doi.org/10.1111/j.1728-4465.2015.00041.x

- Daire, J., Kloster, M. O. \& Storeng, K. T. (2018). Political priority for abortion law reform in Malawi: Transnational and national influences. Health and Human Rights Journal, 03. https:// www.hhrjournal.org/2018/03/politicalpriority-for-abortion-law-reform-in-malawitransnational-and-national-influences/

- Danida (2017) The World 2030: Denmark's strategy for development cooperation and humanitarian action. Ministry of Foreign Affairs of Denmark. https://amg.um.dk/en/ policies-and-strategies/stategy-for-danishdevelopment-cooperation

- Edmonds, E. V., Feigenberg, B. \& Leight, J. (2020). Advancing the agency of adolescent girls (NBER Working Paper No. 27513). Cambridge MA National Bureau of Economic Research. https:// www.nber.org/papers/w27513\#: :text=Can\%20 life $\% 20$ skills\%20be\%20taught,2\%2C459\%20 girls\%20in\%20Rajasthan\%2C\%2OIndia

- Fraser, A., Huchko, M. J., Gipson, J. D., Withers, M., Lewis, S., Ciaraldi, E. J. \& Upadhyay, U. D. (2017). Women's empowerment and family planning: A review of the literature. Journal of Biosocial Science 49, 713-743. https://pubmed. ncbi.nlm.nih.gov/28069078/
- Global Education Evidence Advisory Panel. (2020). Cost-Effective approaches to improve global learning. What does recent evidence tell us are "Smart Buys" for improving learning in low- and middle-income countries? World Bank, FCDO, Building Evidence in Education. https://www.worldbank.org/en/topic/ teachingandlearning/publication/cost-effectiveapproaches-to-improve-global-learning

- Grover, D. (2014, 13 October). What is the Demographic Transition Model? [Blog] PopEd. https://populationeducation.org/whatdemographic-transition-model/

- Hamdallah, M., Foehringer Merchant, H., Cree E. and Harris, N. (2017). The added value of integrating family planning into communitybased services: Learning from implementation. Arlington VA: Advancing Partners \&

Communities. https://www.advancing partners. org/sites/default/files/technical-briefs/apc_ brief_integrating_family_planning.pdf

- Handa, S., Peterman, A., Huang, C., Halpern. C., Pettifor, A. \& Thirumurthy, H. (2015). Impact of the Kenya Cash Transfer for Orphans and Vulnerable Children on early pregnancy and marriage of adolescent girls. Social Science and Medicine, 141, 36-45. https://www.ncbi.nlm.nih gov/pmc/articles/PMC4659857/

- Hardee, K., Patterson, K. P., Schenck-Fontaine, A., Hess, S., Leisher, C., Mutunga, C., Margoluis, C. \& Honzak, C. (2016). Men as contraceptive users: Programs, outcomes and recommendations. Population Council, The Evidence Project. https://evidenceproject.popcouncil.org/wpcontent/uploads/2016/09/Men-as-FP-Users_ September-2016.pdf

- Human Rights Watch. (2018). Leave no girl behind in Africa. Discrimination in Education against Pregnant Girls and Adolescent Mothers. https://www.hrw.org/report/2018/06/14/leave no-girl-behind-africa/discrimination-educationagainst-pregnant-girls-and 
- International Commission on Financing Global Education Opportunity. (2016). The learning generation: Investing in education for a changing world. https://report.educationcommission.org/ downloads/

- Johns Hopkins Center for Communication Programs (2019) Multi-sectoral integration of SBC programming: A high-level

exploration of integrating family planning with other development sectors. https:// www.thecompassforsbc.org/sbcc-tools/ multisectoral-integration-sbc-programminghigh-level-exploration-integrating-family

- Karra, M., Canning, D. \& Wilde, J. (2017). The effect of fertility decline on economic growth in Africa: A macrosimulation model. Population and Development Review, 43, 237-263. https://www. jstor.org/stable/26622881? seq =1

- Keleher, L. (2014). Sen and Nussbaum Agency and capability - expansion. Éthique et économique = Ethics and economics 11(2). Centre de recherche en éthique de l'Université de Montréal. http://hdl.handle.net/1866/10936

- Kim, J. (2016). Female education and its impact on fertility (IZA World of Labor No. 228). IZA World of Labor. https://wol.iza.org/uploads/ articles/228/pdfs/female-education-and-itsimpact-on-fertility.pdf

- Kingdon, J. W. (1984). Agendas, alternatives, and public policies, Boston MA: Little, Brown.

- Lantos, L. (2019, 19 September). Rwanda: A pioneer of family planning in sub-Saharan Africa. [Blog] The Overpopulation Project. https:// overpopulation-project.com/one-of-the-mostefficient-family-planning-programs-in-theworld-rwanda/

- Lee, M., Patierno, K. \& Madsen, E. L. (2020). Investments in family planning and education drive labor productivity. Population Reference Bureau, USAID, PACE.
- Liu, D. H. \& Raftery, A. E. (2020). How do education and family planning accelerate fertility decline? Population and Development Review. 46(3), 409-442. https://idp.sussex.ac.uk/idp/ profile/SAML2/POST/SSO?execution=e1s2

- Lutz, W., Cuaresma, J. S., Kebede, Prskawetz, A., Sanderson, W. C. \& Striessnig, E. (2019). Education rather than age structure brings demographic dividend. PNAS, 116(26). www. pnas.org/cgi/doi/10.1073/pnas.1820362116

- Malacher, S. \& Polis, C. B. (2014). Using measurements of unmet need to inform program investments for health service integration. Studies in Family Planning, 45(2), 263-275. https://pubmed.ncbi.nlm.nih.gov/24931079/

- Malhotra, A. \& Elnakib, S. (2021). 20 Years of the evidence base on what works to prevent child marriage: A systematic review. Journal of Adolescent Health. https://www.jahonline.org/ article/S1054-139X(20)30686-8/fulltext

- Marphatia, A. A., Saville, N. M., Amable, G. S., Manadhar, D. S., Cartina-Borja, M., Wells, J. C. \& Reid, A. M. (2019). How much education is needed to delay women's age at marriage and first pregnancy? Front Public Health, 7, 396. https://doi.org/10.3389/fpubh.2019.00396

- Mason, A., Lee, R. \& Jiang, J. X. (2016). Demographic dividends, human capital and saving. Journal of the Economics of Ageing, 7, 106-122. https://www. sciencedirect.com/science/article/pii/ 2212828X16000050?via\%3Dihub

- MasterCard Foundation. (2020). Secondary education in Africa. Preparing youth for the future of work. https://mastercardfdn.org/ research/secondary-education-in-africa/

- Maswikwa, B., Richter, L., Kaufman, J. \& Nandi, A. (2015). Minimum marriage age laws and the prevalence of child marriage and adolescent births: Evidence from sub-Saharan Africa. International Perspectives on Sexual and Reproductive Health, 41(2), 58-68. https:// pubmed.ncbi.nlm.nih.gov/26308258/
May, J. F. (2017). The politics of family planning policies and programs in sub Saharan Africa. Population and Development Review, 43(S1). https://doi.org/10.1111/j.1728-4457.2016.00165.x

- Mayhew, S. H., Warren, C. E., Ndwiga, C. Narasimhan, M., Wilcher, R., Abuya, T. \& Colombini, M. (2020). Health systems software factors and their effect on the integration of sexual and reproductive health and HIV services. The Lancet, 7(10), E711-E720. https://www thelancet.com/journals/lanhiv/article/PIIS23523018(20)30201-0/fulltext

- Mbizvo, M. T. \& Phillips, S. J. (2014). Family planning: Choices and challenges for developing countries. Best Practice \& Research Clinical Obstetrics \& Gynaecology, 28(6), 931-943. https://www.sciencedirect.com/science/article/ abs/pii/S1521693414000868

- Merrick, T. W. (2002). Population and poverty: New views on an old controversy, International Family Planning Perspectives, 28(1), 41-46. https://doi.org/10.2307/3088274

- Muribu, F. (2020, 10 April). A multisectoral approach to addressing women's barriers to family planning: How the APC project did it in Uganda. [Blog] Knowledge Success. https:// knowledgesuccess.org/2020/04/10/a multisectoral-approach-to-addressingwomens-barriers-to-family-planning-how-theapc-project-did-it-in-uganda/

- Nalwadda, G., Mirembe, F., Byamugisha J. \& Faxelid, E. (2010). Persistent high fertility in Uganda: Young people recount obstacles and enabling factors to use of contraceptives. BMC Public Health 10(530). https://bmcpublichealth.biomedcentral.com/ articles/10.1186/1471-2458-10-530

O'Driscoll, D. (2020). The relationship between population growth, age structure, conflict and governance in sub-Saharan Africa (K4D Emerging Issues Report No. 38). Brighton, UK: Institute of Development Studies. https://opendocs.ids.ac.uk/opendocs/ handle/20.500.12413/15755
Pradhan, E. \& Canning, D. (2015). The effect of schooling on teenage fertility: Evidence from the 1994 education reform in Ethiopia (PGDA Working Paper No. 128). https://cdn1.sph.harvard.edu/ wp-content/uploads/sites/1288/2012/11/ PGDA_WP_128_Pradhan_Canning.pdf

Price, R. A. (2020). The linkages between population change and climate change in Africa (K4D Helpdesk Report No. 900). Brighton, UK: Institute of Development Studies. https://opendocs.ids.ac.uk/opendocs/ handle/20.500.12413/15835

- Psacharopoulos, G. \& Patrinos, H.A. (2004). Returns to investment in education: A further update. Education Economics, 12(2), 111-134. https://doi.org/10.1080/0964529042000239140

- Quak, E. (2021). The link between demography and labour markets in sub-Saharan Africa (K4D Helpdesk Report No. 911). Brighton, UK: Institute of Development Studies. https://opendocs.ids. ac.uk/opendocs/handle/20.500.12413/15931

- Quak, E. \& Tull, K. (2020). Evidence of successful interventions and policies to achieve a demographic transition in sub-Saharan Africa: Ethiopia, Rwanda, and Malawi (K4D Emerging Issues Report No. 30). Brighton, UK: Institute of Development Studies. https://opendocs.ids. ac.uk/opendocs/handle/20.500.12413/15426

- Rosen, J. E., Pappa, S., Vazzano, A. \& Neason, E. (2017). Comparative analysis: Policies affecting family planning access for young women in Guatemala, Malawi, and Nepal. Washington, D. C.: Palladium, Health Policy Plus. http://www. healthpolicyplus.com/ns/pubs/2091-2144_ ComparativeAnalysisYouthPolicyMar.pdf

- Schuler, S.R., Rottach, E., Mukiri, P. (2011) Gender norms and family planning decisionmaking in Tanzania: A qualitative study. Journal of Public Health in Africa 2(2). https:// publichealthinafrica.org/index.php/jphia/article/ view/jphia.2011.e25 
- Schwandt, H. M., Feinberg, S., Akotiah, A., T. Y., Gardner, V. E., Imbabazi, C., McQuin, E., Mohamed M., Rugoyera, A., Musemakweli, D., Nichols, C. W., Nyangezi, N. U., Arizmendi, J. S., Welikala, D., Yamuragiye, B. \& Zigo, L. (2018). Family planning in Rwanda is not seen as population control, but rather as a way to empower the people: Examining Rwanda's success in FP from the perspective of public and private stakeholders. Contraceptive Reproduction Medical, 3(18). https://doi.org/10.1186/s40834-018-0072-y

- Sedgh, G. \& Hussain, R. (2014). Reasons for contraceptive nonuse among women having unmet need for contraception in developing countries. Studies in Family Planning, 45(2), 151169. https://pubmed.ncbi.nlm.nih.gov/24931073/

- Sen, A. (1999). Development as freedom. New Yor NY: Alfred A. Knopf

- Shapiro, D. (2017). Linkages between education and fertility in sub-Saharan Africa (AFD Research Paper Series No. 56). Agence Française de Développement.https://www.afd.fr/en/

ressources/linkages-between-education-andfertility-sub-saharan-africa

- Sinding. S. W. (2009). Population, poverty and economic development. Philosophical Transactions of the Royal Society $B$ : Biological Sciences, 364(1532). https:// royalsocietypublishing.org/doi/10.1098/ rstb.2009.0145

- Sullivan Robinson, R. (2012). Negotiating development prescriptions: The case of population policy in Nigeria. Population Research and Policy Review, 31, 267-296. https://link. springer.com/article/10.1007/s11113-011-9222-5

- Sully, E. A., Biddlecom, A., Darroch, J. E., Riley, T., Ashford, L. S., Lince-Deroche, N., Firestein, L. \& Murro, R. (2020). Adding it up: Investing in sexual and reproductive health 2019. New York NY: Guttmacher Institute. https://www.guttmacher. org/report/adding-it-up-investing-in-sexualreproductive-health-2019
- The Guardian (2018, 26 September) More choice would mean fewer children in Africa. https://www.theguardian.com/globaldevelopment/2018/sep/26/education-familyplanning-key-africa-future-emmanuel-macronun-general-assembly

- UN Women. (2002). Gender mainstreaming: An overview, New York NY: United Nations Office of the Special Adviser on Gender Issues, Department of Economic and Social Affairs. https://www.un.org/womenwatch/osagi/pdf/ e65237.pd

- UNESCO GEM. (2020). Global education monitoring report summary, 2020. Inclusion and education: all means all. https://unesdoc. unesco.org/ark:/48223/pf0000373721

- UNFPA. (2012). Impacts of population dynamics reproductive health and gender on poverty. New York NY: United Nations Population Fund. https://www.unfpa.org/publications/impactspopulation-dynamics-reproductive-health-andgender-poverty

- UNICEF. (2021, March). COVID-19: A threat to progress against child marriage. https://data. unicef.org/resources/covid-19-a-threat-toprogress-against-child-marriage/

- United Nations. (2018). World population policies 2015: Highlights (ST/ESA/SER.A/373). Department of Economic \& Social Affairs. Population Division. https://www.un.org/ development/desa/pd/sites/www.un.org. development.desa.pd/files/wpp2015_ highlights.pdf

- United Nations WOMEN (2001). Gender Mainstreaming - An Overview. New York, UN. https://www.un.org/womenwatch/osagi/ conceptsandefinitions.htm

- Upadhyay, U. \& Karasek, D. (2012). Women's empowerment and ideal family size: An examination of DHS empowerment measures in sub-Saharan Africa. International Perspectives on Sexual and Reproductive Health, 38(2), 7889. https://pubmed.ncbi.nlm.nih.gov/22832148/
- USAID. (2017). Economic empowerment: A pathway for women and girls to gain control over their sexual and reproductive health. Evidence Summary. High Impact Practices in Family Planning (HIPs). https://www. fphighimpactpractices.org/briefs/economicempowerment/

- USAID. (2014). Male engagement in family planning: Reducing unmet need for family planning by addressing gender norms. Policy Brief for USAID, published by Institute for Reproductive Health, Georgetown University. http://irh.org/wp-content/uploads/2014/10/ Male_Engagement_in_FP_Brief_10.10.14.pd

- USAID (2013). Family planning policy: Building the foundation for systems, services, and supplies. http://www.fphighimpactpractices. org/briefs/policy/

Vanwesenbeeck, I., Westeneng, J., de Boer, T., Reinders, J. \& van Zorge, R. (2016). Lessons learned from a decade implementing Comprehensive Sexuality Education in resource poor settings: The World Starts With Me. Sex Education, 16(5), 471-486. https://www.

tandfonline.com/doi/full/10.1080/14681811.201 5.1111203

- Walker, J-A. (2012). Early marriage in Africa - trends, harmful effects and interventions. African Journal of Reproductive Health, 16(2). 231-240. https://www.jstor.org/stable/23318031

- Wardrop. N. A., Jochem. W. C., Bird, T. J. Chamberlain, H. R., Clarke, D., Kerr, D. Bengtsson, L., Juran, S., Seaman, V. \& Tatem, A. J. (2018). Spatially disaggregated population estimates in the absence of national population and housing census data. Proceedings of the National Academy of Sciences (PNAS) 115(14), 3529-3537. https://www.pnas.org/ content/115/14/3529
- Warren, C. E., Hopkins, J., Narasimhan, M., Collins, L., Askew, I. \& Mayhew, S. H. (2017). Health systems and the SDGs: Lessons from a joint HIV and sexual and reproductive health and rights response. Health Policy and Planning 32(suppl. 4), iv102-iv107. https://academic.oup. com/heapol/article/32/suppl_4/iv102/4661667

- Watkins, S. \& Kaler, A. (2016). Pivoting to learning: A puzzle with many pieces (RISE Working Paper No. 16/006). RISE. https://riseprogramme.org/ sites/default/files/publications/RISE_WP-006Watkins-Kaler_0.pdf

- Wietzke, F. B. (2020). Poverty, inequality, and fertility: The contribution of demographic change to global poverty reduction. Population and Development Review, 46(1), pp. 65-99. https://doi.org/10.1111/padr.12317

- Wodon, Q., Montenegro, C., Nguyen, H. \& Onagoruwa, A., (2018). Missed opportunities: The high cost of not educating girls (The Cost of Not Educating Girls Notes Series). Washington, D.C. World Bank. http://hdl.handle.net/10986/29956 - Woodhill, J. \& Quak, E. (2019). Changing food systems: Implications for DFID priorities (Policy Brief). Brighton, UK: Institute of Development Studies. https://opendocs.ids.ac.uk/opendocs/ handle/20.500.12413/14703

- World Bank (2018). Incentives for Improving Birth Registration Coverage: A Review of the Literature. World Bank Group. http:// documents1.worldbank.org/curated/ en/928651518545413868/Incentives-forImproving-Birth-Registration-Coverage-AReview-of-the-Literature.pdf

- WYG International (2019). What influences policymakers' behaviour in Zambia? An account of two cases. Evaluation of the DFID Zambia Accountability Programme.

- Zahariadis, N. (2016). Handbook of public policy agenda setting. Edward Elgar. https://www.elgaronline.com/view/ edcoll/9781784715915/9781784715915.xml 


\section{Contact}

Email info@k4d.info

Twitter @K4D_info

Website www.ids.ac.uk/k4d

NVI 